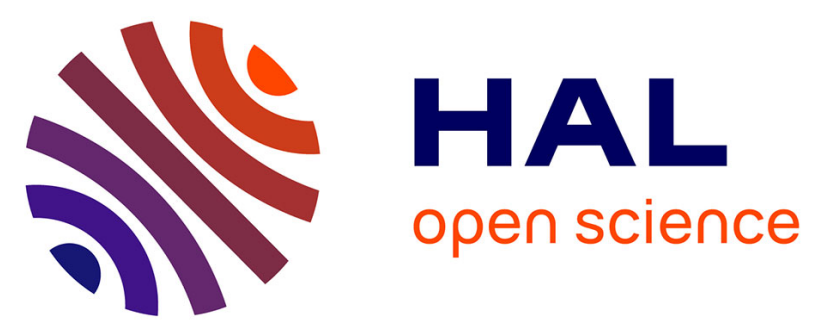

\title{
A large scale proteome analysis of the gefitinib primary resistance overcome by KDAC inhibition in KRAS mutated adenocarcinoma cells overexpressing amphiregulin
}

Sylvia Lehmann, Michel Seve, Laetitia Vanwonterghem, Sylvie Michelland, Valérie Cunin, Jean-Luc Coll, Amandine Hurbin, Sandrine Bourgoin-Voillard

\section{To cite this version:}

Sylvia Lehmann, Michel Seve, Laetitia Vanwonterghem, Sylvie Michelland, Valérie Cunin, et al.. A large scale proteome analysis of the gefitinib primary resistance overcome by KDAC inhibition in KRAS mutated adenocarcinoma cells overexpressing amphiregulin. Journal of Proteomics, 2019, 195, pp.114-124. 10.1016/j.jprot.2019.01.009 . hal-01987911

\section{HAL Id: hal-01987911 \\ https://hal.univ-grenoble-alpes.fr/hal-01987911}

Submitted on 20 Jan 2020

HAL is a multi-disciplinary open access archive for the deposit and dissemination of scientific research documents, whether they are published or not. The documents may come from teaching and research institutions in France or abroad, or from public or private research centers.
L'archive ouverte pluridisciplinaire HAL, est destinée au dépôt et à la diffusion de documents scientifiques de niveau recherche, publiés ou non, émanant des établissements d'enseignement et de recherche français ou étrangers, des laboratoires publics ou privés. 


\title{
A Large Scale Proteome Analysis
}

\section{of the Gefitinib Primary Resistance Overcome by}

\author{
KDAC Inhibition in KRAS Mutated
}

\section{Adenocarcinoma Cells Overexpressing}

\section{Amphiregulin}

Sylvia G Lehmann ${ }^{1,2,3,4}$; Michel Seve 1,2,3 ${ }^{\text {L Laetitia Vanwonterghem }}{ }^{5}$; Sylvie Michelland ${ }^{1,2}$,

${ }_{3 *}^{3}$; Valérie Cunin ${ }^{1,2,3}$; Jean-Luc Coll ${ }^{5}$; Amandine Hurbin ${ }^{5 *}$; Sandrine Bourgoin-Voillard ${ }^{1,2}$

${ }^{1}$ Univ. Grenoble Alpes, LBFA and BEeSy, PROMETHEE Proteomic Platform, Grenoble, France

${ }^{2}$ Inserm, U1055, PROMETHEE Proteomic Platform, Grenoble, France

${ }^{3}$ CHU Grenoble Alpes, Institut de Biologie et de Pathologie, PROMETHEE Proteomic Platform, Grenoble, France

${ }^{4}$ Univ. Grenoble Alpes, ISTerre, F-38000 Grenoble, France

${ }^{5}$ Cancer target and experimental therapeutics, Institute for Advanced Biosciences, INSERM

U1209, CNRS UMR5301, Univ. Grenoble Alpes, F-38000 Grenoble, France.

* Co-last and co-corresponding authors.

\section{Correspondence :}

Sandrine Bourgoin-Voillard,

Platform of Medical Proteomics Facility, Institut de Biologie et Pathologie, CHU de Grenoble Alpes, Boulevard la Chantourne, 38700 La Tronche, France

Tel: $+33(0) 476765844$

E-mail: sandrine.bourgoin@univ-grenoble-alpes.fr

Amandine Hurbin

Institute for Advanced Biosciences

Univ. Grenoble Alpes, INSERM U1209, CNRS UMR5301

Site Santé, Allée des Alpes, 3700 La Tronche, France

Tel: +33 (0)4 76549553

E-mail: amandine.hurbin@univ-grenoble-alpes.fr 


\section{Biological significance}

In this article, we revealed the first large-scale analysis of cytoplasmic and nuclear proteome regulations in the context of NSCLC resistance to gefitinib in H358 KRAS mutated and amphiregulin-overexpressing NSCLC cells. Our data provide new insights into proteome dysregulation when apoptosis was restored by deacetylase inhibitors and gefitinib. It also demonstrated that eEF1A2 and STAT1, that are dysregulated after gefitinib sensitivity restoration, did not directly control EGFR-TKI resistance through apoptosis process, but both are related to AKT phosphorylation known to act on apoptosis inhibition. 


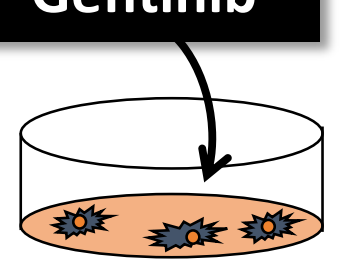

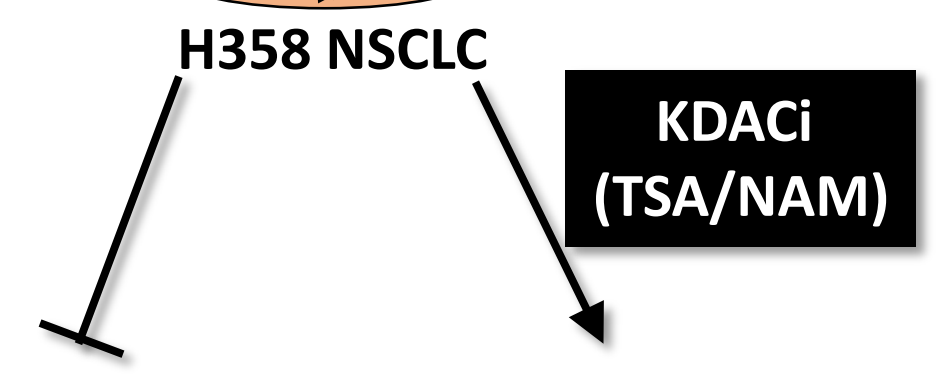

APOPTOSIS

\section{APOPTOSIS}

$+$

proteome dysregulation

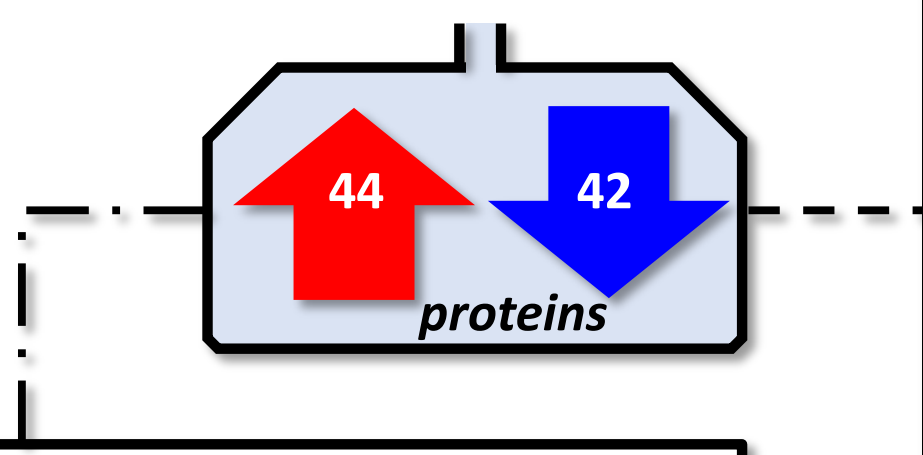

Metabolic process

Cell cycle/Chromosome segregation

Development process /Cell death ...

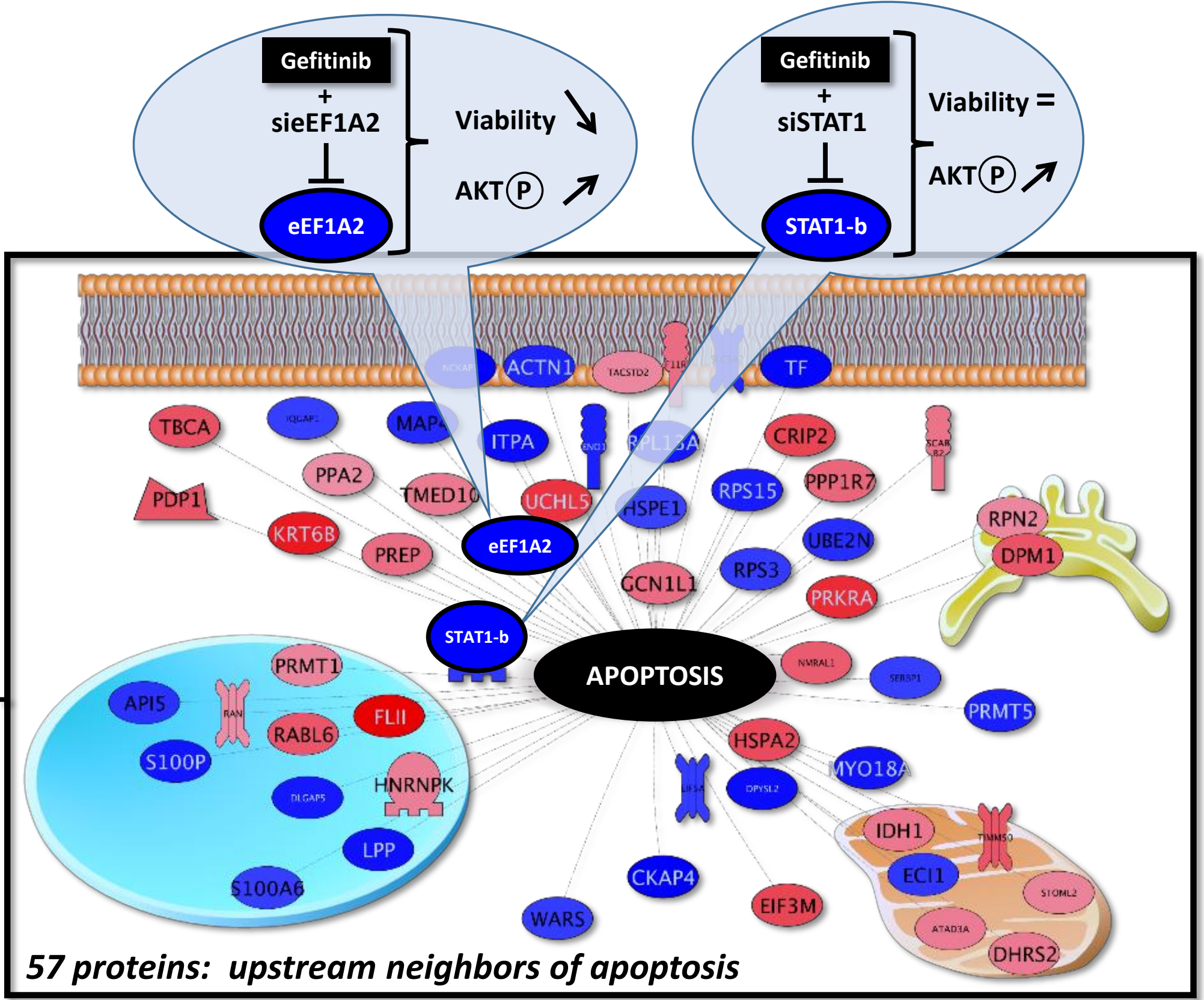




\section{Highlights}

- A better understanding of EGFR-TKI resistance mechanisms in KRAS mutated and amphiregulin-overexpressing non-small cell lung cancer cell (NSCLC)

- An identification of some putative protein biomarkers involved in the restoration of sensitivity to EGFR-TKI by deacetylase inhibitors, to provide new therapeutic protein targets for KRAS mutated NSCLC patients, who have a poor prognosis.

- eEF1A2 and STAT1 are related to AKT phosphorylation involved in EGFR-TKI resistance. 


\section{Abstract}

KDAC inhibitors (KDACi) overcome gefitinib primary resistance in non-small cell lung cancer (NSCLC) including mutant-KRAS lung adenocarcinoma. To identify which proteins are involved in the restoration of this sensitivity and to provide new therapeutic targets for mutant-KRAS lung adenocarcinoma, we performed an iTRAQ quantitative proteomic analysis after subcellular fractionation of H358-NSCLC treated with gefitinib and KDACi (TSA/NAM) versus gefitinib alone. The 86 proteins found to have been significantly dysregulated between the two conditions, were mainly involved in cellular metabolism and cell transcription processes. As expected, the pathway related to histone modifications was affected by the KDACi. Pathways known for controlling tumor development and (chemo)resistance (miRNA biogenesis/glutathione metabolism) were affected by the KDACi/gefitinib treatment. Moreover, 57 dysregulated proteins were upstream of apoptosis (such as eEF1A2 and STAT1) and hence provide potential therapeutic targets. The inhibition by siRNA of eEF1A2 expression resulted in a slight decrease in H358-NSCLC viability. In addition, eEF1A2 and STAT1 siRNA transfections suggested that both STAT1 and eEF1A2 prevent AKT phosphorylation known for enhancing gefitinib resistance in NSCLC. Therefore, altogether our data provide new insights into proteome regulations in the context of overcoming the NSCLC resistance to gefitinib through KDACi in H358 KRAS mutated and amphiregulin-overexpressing NSCLC cells.

Keywords: Non-small cell lung cancer; EGFR-TKI; resistance; gefitinib; inhibitors of lysine deacetylases; quantitative proteomics 


\section{Abbreviations:}

ACN: acetonitrile

BAX: Bcl-2-associated X

BRAF: v-raf murine sarcoma viral oncogene homolog B1

eEF1A2: elongation factor 1-alpha 2

EGF: epidermal growth factor

EGFR: epidermal growth factor receptor

EGFR-TKI: EGFR-tyrosine kinase inhibitor

FDR: false discovery rate

iTRAQ: isobaric tags for relative and absolute quantitation

KDAC: lysine deacetylases

KDACi: lysine deacetylases inhibitor

KRAS: kirsten rat sarcoma viral oncogene homolog

LC: liquid chromatography

miRNA: microRNA

MS: mass spectrometry

NAM: nicotinamide

NSCLC: non-small cell lung cancer

PBS: phosphate buffered saline

PI3K: phosphatidylinositol-3-kinase

PTEN: phosphatase and tensin homolog

siRNA: small interfering ribonucleic acid

STAT1: signal transducer and activator of transcription 1-alpha/beta

TCEP: tris(2-carboxyethyl)phosphine

TFA: trifluoroacetic acid

TGF-beta: transforming growth factor beta

TSA: trichostatin A 


\section{Introduction}

Lung cancer is the leading cause of cancer-related adult deaths worldwide.[1][2] Treatment of selected patients with advanced non-small cell lung cancers (NSCLCs) was revolutionized by the discovery and subsequent targeting of the epidermal growth factor receptor (EGFR) pathway. Gefitinib and erlotinib are EGFR-tyrosine kinase inhibitors (EGFR-TKIs) that improve the survival of patients with EGFR-mutated NSCLCs. However, the limited response to EGFR-TKIs observed in patients with wild-type EGFR NSCLC showed that there were intrinsic resistance mechanisms to EGFR-TKIs.[3] Such primary resistance was also commonly related to mutations of EGFR (T790M), KRAS (Kirsten rat sarcoma viral oncogene homolog), BRAF (v-raf murine sarcoma viral oncogene homolog B1) and PI3K (phosphatidylinositol-3-kinase) genes or amplification of MET, amphiregulin and insulin-like growth factor-1 receptor proteins or loss of PTEN protein.[4][5][6][7][8] In this context, we previously described the beneficial role of lysine deacetylases (KDACs) in the EGFR-TKI primary resistance of mutant $K R A S$ lung adenocarcinoma. It should be noted that human KDACs may also be named histone deacetylases (HDACs) and are grouped into four classes: Class I, class II and class IV KDACs are named classical KDACs and are involved in the development of lung cancers. Class III KDACs (also called sirtuins) are implicated in important cellular processes. In our previous study, we reported that the four classes of KDACi strongly sensitized NSCLC tumors and hepatocarcinoma to EGFR-TKI treatment with gefitinib, both in vitro and in vivo.[9][10] We also demonstrated that the four classes of KDAC inhibitors (KDACi) significantly sensitized mutant KRAS adenocarcinoma cells to gefitinib through an amphiregulin-dependant pathway.[9][10][11] The combination of KDAC inhibitors with gefitinib induced apoptosis in mutant $K R A S$ adenocarcinoma cell lines through the inhibition of the PI3K/AKT survival pathway and the regulation of the $\mathrm{BAX} / \mathrm{Ku} 70$ interaction in an acetylation-dependent manner. This suggests that the effects of KDAC 
inhibitors may be considerably broader and more complicated than originally thought. Other researchers confirmed this view and reported that classes I/II/III/IV KDAC inhibitors may affect gene expression profile[12] as well as protein expression level.[13][14][15][16] For instance, classes I/II KDACi may inhibit cell growth by upregulating anti-oxidant proteins such as peroxiredoxin 1 and 2 and glutathione S-transferase in lymphoid malignant cells.[14] Others reported that classes I/II KDACi induced, in multiple myeloma, an activation of apoptotic cascades by inhibiting the proteasomal and aggresomal protein degradation systems leading to an accumulation of poly-ubiquitinated proteins, and thereby, a significant cell stress and cytotoxicity. [15] More recently, Mackmull et al.[16] utilized a large scale proteomic study to demonstrate that classes I/II/III/IV KDACi altered the expression level of nuclear proteins in HeLa cells mostly by a selective depletion of bromodomain containing proteins (BCPs), other chromatin regulators and transcription factors. While it is now established that KDACi may affect the acetylation of proteins (histone and non-histone proteins), signaling pathway, gene expression level and protein expression level, the effects of KDACi on the proteome are not completely elucidated in the context of overcoming the resistance to gefitinib in NSCLC.

Based on a large-scale proteome analysis of H358 NSCLC known as resistant to gefitinib due to KRAS mutation and amphiregulin overexpression, this study aims to highlight how the proteome is affected when KDACi overcome these primary resistance to gefitinib in lung adenocarcinoma cells. This proteome analysis proposes to obtain a better understanding of resistance mechanisms to gefitinib treatment so as to help in identifying some protein putative biomarkers of the restored sensitivity to gefitinib by deacetylase inhibitors treatment. This strategy should provide new therapeutic protein targets for the subset of NSCLC patients, who have a poor prognosis with current gefitinib therapy. We used subcellular fractionation followed by the iTRAQ method to perform quantitative nuclear and cytoplasmic protein 
profiling of the mutant KRAS adenocarcinoma H358 cells treated with gefitinib and deacetylase inhibitors in combination, or with gefitinib alone. As previous studies showed that the two KDACi trichostatin A (TSA) and nicotinamide (NAM) are required concomitantly to induce cell death in NSCLC cells and avoid any compensation of KDAC inhibition between the four classes of KDAC, we used in this study concomitantly TSA and NAM KDACi to target I/II/IV KDAC and class III KDAC, respectively. In this context, we demonstrated that the expression level of 71 proteins in the cytoplasm and 15 proteins in the nucleus was affected by KDACi. These proteins are mostly involved in cellular metabolism and cell transcription biological processes. As expected, the pathway related to histone modifications was affected by the KDACi treatment. More interestingly, pathways known for acting in the development of tumors and (chemo)resistance (miRNA biogenesis, glutathione metabolism) were also affected by the KDACi/gefitinib treatment. In addition, 57 dysregulated proteins were known as upstream neighbors of apoptosis, which suggested these could be interesting therapeutic targets. The dysregulation of three interesting proteins were further validated by Western blot analyses. SiRNA transfection allowed us to observe a slight effect of eEF1A2 on H358 cell viability, while no direct effect on apoptosis was reported for STAT1 siRNA. Interestingly, AKT phosphorylation already known for its implication in the resistance to gefitinib seems to be intimately linked to the expression level of both eEF1A2 and STAT1 proteins. Thus, herein, we report new insights on the effects of KDACi on the proteome in the context of overcoming the NSCLC resistance to gefitinib in H358 KRAS mutated and amphiregulin-overexpressing NSCLC cells that may be helpful to design improved cancer therapies. 


\section{Material and Methods}

\section{Cell culture and drug treatments}

The human H358 NSCLC cell line was purchased from the American Type Culture Collection (ATCC, Manassas, VA) and was authenticated by DNA STR profiling (ATCC Cell line Authentification Service, LGC Standard SARL, Molsheim, France). H358 cells were routinely tested for the presence of mycoplasma (MycoAlert ${ }^{\circledR}$ Mycoplasma Detection kit, Lonza, France). H358 cells were cultured in RPMI 1640 medium (Gibco, Cergy Pontoise, France) supplemented with $10 \%$ heat-inactivated fetal bovine serum at $37^{\circ} \mathrm{C}$ in a humidified incubator with $5 \% \mathrm{CO}_{2}$. $\mathrm{H} 358$ cells were treated with $200 \mathrm{ng} / \mathrm{mL}$ trichostatin A (TSA) (an inhibitor of class I/II KDAC) and $5 \mathrm{mM}$ nicotinamide (NAM) (a class III KDAC inhibitor) and/or $0.5 \mu \mathrm{M}$ gefitinib (EGFR-TKI) for 96 hours. Trichostatin A and nicotinamide were purchased from Sigma-Aldrich (St Quentin-Fallavier, France) and gefitinib from Selleckchem (Munich, Germany). To highlight which biological effects are linked to restoration of gefitinib sensitivity upon KDACi and not on the sensitivity of KDAC inhibitors alone (TSA and NAM), additional control cells were prepared under KDAC inhibitor treatment without gefitinib treatment: $200 \mathrm{ng} / \mathrm{mL}$ TSA for 96 hours, $5 \mathrm{mM}$ NAM for 96 hours, combination of $200 \mathrm{ng} / \mathrm{mL}$ TSA and 5 mM NAM for 96 hours. H358 NSCLC cells were also treated with gefitinib and each TSA/NAM KDACi separately as following: $200 \mathrm{ng} / \mathrm{mL}$ TSA0.5 $\mu \mathrm{M}$ gefitinib (EGFR-TKI) for 96 hours, $5 \mathrm{mM} \mathrm{NAM}$ and $0.5 \mu \mathrm{M}$ gefitinib (EGFR-TKI) for 96 hours.

\section{Subcellular fractionation}

After treatment, medium was collected and cells were washed with PBS and harvested by trypsinization. After centrifugation, pelleted cells were then pooled and washed three times with cold PBS. Cells were incubated with hypotonic buffer (10 mM Hepes pH 7.9, $10 \mathrm{mM}$ 
$\mathrm{KCl}, 1.5 \mathrm{mM} \mathrm{MgCl} 2,0.2 \mathrm{mM}$ TCEP, $50 \mathrm{ng} / \mathrm{mL}$ TSA, $1.25 \mathrm{mM}$ nicotinamide) supplemented with protease and phosphatase inhibitor cocktail (cOmplete and PhosSTOP, Roche) for 15 minutes on ice, centrifuged and then incubated with hypotonic buffer containing $0.5 \%$ NP40 for 10 minutes on ice. After centrifugation, the supernatant contained the cytoplasmic proteins. The pellet was further washed three times with cold PBS, incubated with a lysis buffer $(50 \mathrm{mM}$ Tris- $\mathrm{HCl} \mathrm{pH}$ 7.4, $150 \mathrm{mM} \mathrm{NaCl}, \quad 1 \%$ Nonidet P-40, 0.5\% sodium deoxycholate, $0.1 \%$ sodium dodecyl sulfate, $50 \mathrm{ng} / \mathrm{mL}$ TSA, $1.25 \mathrm{mM}$ nicotinamide, protease and phosphatase inhibitor cocktail) for 30 minutes on ice, and sonicated. After centrifugation, the supernatant contained the nuclear proteins. Protein extracts were stored at $-20^{\circ} \mathrm{C}$.

\section{Protein digestion and iTRAQ labeling}

Protein concentration of cytoplasmic and nuclear extracts was determined by a BCA protein assay kit (Thermo Fischer Scientific, IL, USA). One hundred $\mu \mathrm{g}$ of protein per sample were reduced, alkylated, digested with trypsin (Promega) and labeled with isobaric tagging reagents according to the manufacturer's specifications (iTRAQ Reagents 8 plex Applications kit; Sciex, Framingham, MA, USA). Nuclear and cytoplasmic extracts were analyzed in separate analyses but using the same reporter for the same condition. Samples from gefitinib treated cells were labeled with the iTRAQ reporter ion at $m / z 117.1$ and deacetylase inhibitors and gefitinib co-treatment with the reporter ion at $\mathrm{m} / \mathrm{z}$ 121.1. Control cells prepared without gefitinib treatment were labeled as following: reporter ion at $m / z, 113$ (no KDACi treatment); reporter ion at $m / z 114(200 \mathrm{ng} / \mathrm{mL}$ TSA for 96 hours), reporter ion at $m / z, 115$ (5 mM NAM for 96 hours), reporter ion at $\mathrm{m} / z 116$ (200 ng/mL TSA and $5 \mathrm{mM} \mathrm{NAM}$ for 96 hours). Control cells prepared with $0.5 \mu \mathrm{M}$ gefitinib for 96 hours were labeled as following: reporter ion at $m / z 118$ (200 ng/mL TSA for 96 hours), reporter ion at $m / z 119$ (5 mM NAM for 96 hours). 


\section{OFFGEL isoelectrofocusing and nano LC-MS/MS analysis}

Samples containing iTRAQ-labeled peptides were then pooled and fractionated, initially depending on their $\mathrm{pI}$ by OFFGEL isoelectrofocusing and then by $\mathrm{C} 18$ reversed-phase nano liquid chromatography (RP-nanoLC). These steps were performed as described previously.[17]'[18] Briefly, peptides were loaded on the 3100 OFFGEL fractionator system with OFFGEL Kit linear pH 3-10 (Agilent technology) in a 24-well setup and a constant current of $50 \mu \mathrm{A}$ was applied until $50 \mathrm{kVh}$ was reached.

After desalting of peptide samples from each well with C18 ZipTips (Millipore, MA, USA), peptides samples were further separated on an Ultimate $3000 \mathrm{C} 18$ RP-nanoLC system (Ultimate 3000, Dionex/Thermo Scientific) controlled by Chromeleon v. 6.80 software (Dionex/Thermo Scientific/LC Packings, Amsterdam, The Netherlands) and coupled to a Probot MALDI spotting device controlled by the $\mu$ Carrier 2.0 software (Dionex/Thermo Scientific/LC Packings, Amsterdam, The Netherlands). Peptides in buffer A ( $2 \%$ ACN, $0.05 \%$ TFA) were loaded on a nano-trapping column $(\mathrm{C} 18,3 \mu \mathrm{m}, 100 \AA$ pore size; LC Packings) in $2 \%$ ACN and $0.05 \%$ TFA at a flow rate of $20 \mu \mathrm{L} / \mathrm{min}$ for $5 \mathrm{~min}$. Then, trapped peptides were separated by reversed phase chromatography (Acclaim PepMap100 $75 \mu \mathrm{m}, 15$ cm, nano-Viper C18, $3 \mu \mathrm{m}, 100 \AA$ pore size; Thermo Scientific) with a binary gradient of buffer A (2\% ACN, $0.05 \%$ TFA) and buffer B ( $80 \% \mathrm{ACN}, 0.04 \%$ TFA) at a flow rate of 0.3 $\mu \mathrm{L} / \mathrm{min}$ set up as follows: 0-5 $\min , 4 \% \mathrm{~B}$; 5-35 $\mathrm{min}, 8-42 \% \mathrm{~B} ; 35-40 \mathrm{~min}, 42-58 \% \mathrm{~B} ; 40-50$ $\min , 58-90 \% \mathrm{~B}$ and $50-60 \mathrm{~min}, 4 \% \mathrm{~B}$. Fractions from eluted solution were collected and spotted on an Opti-tof LC/MALDI Insert 123 x $81 \mathrm{~mm}$ plate (Sciex, Les Ulis, France) at a frequency of one spot per 15 seconds. The $\alpha$-cyano-4-hydroxy-cinnamic acid matrix (HCCA, $2 \mathrm{mg} / \mathrm{mL}$ in $70 \% \mathrm{ACN}$ and $0.1 \% \mathrm{TFA}$ ) was continuously added to the column effluent at a flow rate of $0.9 \mu \mathrm{L} / \mathrm{min}$, and therefore, integrated in each spot of MALDI sample plate 
NanoLC-off-line spotted peptide samples were analyzed in MS and MS/MS using the 4800 MALDI-TOF/TOF mass spectrometer (Sciex, Les Ulis, France) controlled by the 4000 Series Explorer software v. 3.5.3. The mass spectrometer was operated in positive reflector ion mode. External calibration was performed on each plate using the Peptide Calibration Standard II (Bruker Daltonics, Bremen, Germany) and the peptide mass tolerance was set to $50 \mathrm{ppm}$. MS spectra were acquired in an $\mathrm{m} / \mathrm{z}$ range of 700-4000. Up to 40 of the most intense ions per spot position characterized by a $\mathrm{S} / \mathrm{N}$ (signal/noise) ratio higher than 30 were chosen for MS/MS analysis. Selected ions were fragmented by using CID (Collision-Induced Dissociation) activation mode in order to obtain the corresponding MS/MS spectrum required for identification and quantification of peptides, and therefore, corresponding proteins.

\section{MS data processing and bioinformatic analysis}

MS and MS/MS acquired spectra were used for identification and relative quantitation by using ProteinPilot ${ }^{\mathrm{TM}}$ software v. 4.5 with the Paragon ${ }^{\mathrm{TM}}$ Algorithm (Sciex, Les Ulis, France). The analysis was performed with the human database of UniProtKB release 2015_06 /SwissProt (European Bioinformatics Institute, Hinxton, UK). The search effort was set to 'Thorough ID' and a false discovery rate (FDR) of 1\% was applied. For the quantification analysis, bias and background correction were applied and only quantified proteins with at least 1 peptide at the $95 \%$ peptide confidence level were included. In order to obtain high quality in quantitative analysis, we analyzed our data with the R package Isobar v. 1.14.0, [19] which allows the determination of statistical significance of protein/peptide dysregulation. Statistical analysis of R package Isobar is based on three layers of modeling: (1) the noise model for spectra; (2) the protein ratio calculation and its variance that allows the determination of pValueRatio; and (3) the biological sample variability model that allows the determination of $\mathrm{pValueSample.} \mathrm{The} \mathrm{choice} \mathrm{of} \mathrm{significant} \mathrm{protein} \mathrm{dysregulation} \mathrm{is} \mathrm{based}$ 
on pValueRatio and pValueSample considering that both are better than a chosen level of risk, e.g., $5 \%$. The $\mathrm{pValueR}$ atio is estimated by considering a Gaussian distribution of the variance $\operatorname{Var}(\mathrm{c}(\mathrm{p}, \mathrm{i}))$ of protein ratio $\mathrm{c}(\mathrm{p}, \mathrm{i}))[19]$ that indicates ratio accuracy in terms of signal quality (how many spectra, how intense) by combining the ratios measured from the MS/MS spectra of its peptide spectra. To relate this pValueRatio to biological sample variability, the $\mathrm{R}$ package Isobar estimated the pValueSample based on the Cauchy distribution of these random protein ratios. Therefore, a normal distribution was applied and only proteins which ratio had a pValueRatio and a pValueSample $<0.05$ were then considered as significantly differentially expressed depending on treatment. For output of our quantitative iTRAQ results, all protein ratios were expressed as either gefitinib, TSA and NAM versus gefitinib treated cells $(121: 117)$ to provide relative protein quantification ratios. The analysis of the distribution of the number of identified and dysregulated proteins according to their subcellular localization was achieved with the use of BioVenn web application.[20] Proteomic data were submitted to the ProteomeXchange Consortium via the MassIVE Dataset Submission.[21] Data for cytoplasmic extract were registered under the MassIVE identifier MSV000081840 and ProteomeXchange identifier PXD008530 and data for nucleus extract were registered under the MassIVE identifier MSV000081841 and ProteomeXchange identifier PXD008532.

\section{Functional analysis}

Gene ontology analysis was performed using PANTHER (http://www.pantherdb.org/)[22] by importing the list of dysregulated proteins. Each protein was classified in one or several categories regarding the PANTHER Family, Protein class, GO-Slim Molecular function, Biological Process, and Cellular Component and finally Pathway. 
Considering the limited number of dysregulated proteins identified (Tables S1 and S2), we applied a pathway over-representation statistical test using PathVisio 3.2.2 Revision: 4047 [23] by importing the list of dysregulated proteins presented in Tables S1 and S2 against the background proteome. The following criteria have been used [Log10 Ratio] $<-0.15$ or $[\log 10$ Ratio] $>0.16$ and [Is Significant $=1$ and the calculation method was pathway-centric. As considered by Curran et al.,[24] only pathways with a Z-Score of $>1.96$ and a p-value of $<0.05$ were considered as important.

Sub-network analysis was performed with Pathway Studio Mammalian Web 10.3 (Ariadne Genomics ${ }^{\circledR}$ software, Elsevier ${ }^{\circledR}$ Inc, Rockville, MD, USA) with the list of 86 proteins dysregulated and the following parameters: Generate a sub-network with centers downstream of the protein neighbors with all different types of connections listed (chemical reaction, direct regulation, expression, miRNA effect, molecule synthesis, molecule transport, promoter binding, protein modification and regulation). Sub-networks are generated by connecting entities to the neighbours in the ResNet Explore database. A sub-network consists of a regulator and its targets. As we are analysing protein expression data, we selected the option generate sub-network with center downstream of neighbours to identify the processes that are regulating by these proteins and that are modulated by protein expression level.

\section{Cell viability and apoptosis assays}

Treated cells were harvested and cell viability was analyzed at 96 h by Trypan blue exclusion assay (Invitrogen). Three separate experiments were performed, and the results were expressed as the mean $+/-$ SD of the percentage of proliferation compared with the control.

Percentage of apoptosis was scored, as previously described,[10] by the assessment of morphological changes by fluorescence microscopy after Hoechst $33342(5 \mu \mathrm{g} / \mathrm{mL}$, Sigma) staining. At least 500 cells were counted for each condition. Active caspase- 3 was detected by 
flow cytometry using a phycoerythrin-conjugated monoclonal active caspase- 3 antibody kit (BD Pharmingen, Le Pont de Claix, France), following the manufacturer's instructions. The analysis was performed on a BD Accuri C6 flow cytometer with CFlow Plus software (BD Biosciences).

\section{Western blot analysis}

Immunoblotting experiments were performed, as previously described,[10] on nuclear and cytoplasmic extracts for validation of the proteomic results (subcellular localization and level of expression) using antibodies against STAT1, p63- $\alpha$, p-AKT-S ${ }^{473}$, AKT (Cell Signaling Technology, St Quentin en Yvelines, France), eEF1A2 and HSP70 (Thermo Fisher Scientific). alpha-tubulin (Santa Cruz Biotechnology) and Lamin B1 antibodies (Cell Signaling) were used to assess, by Western blot, the purity of the nuclear and the cytoplasmic fractions respectively. The relative intensity, measured using ImageJ (NIH software), of cytoplasmic or nuclear proteins was normalized to the respective alpha-tubulin, HSP70 or Lamin B1.

\section{siRNA transfections}

Small interfering RNAs (siRNAs) targeting human STAT1 or eEF1A2 or non-specific control siRNAs were synthetized by Eurogentec (France). Sequences of siRNAs targeting human STAT1 were 5'-GCU-GGA-UGA-UCA-AUA-UAG-U55-3' and 5'-CUU-ACG-AAC-AUGACC-CUA-U55-3', sequence of siRNA targeting human eEF1A2 was 5'-AAU-GCG-GAGGUA-UUG-ACA-AAA-3', and control siRNA sequence was 5'-CUU-ACG-CUC-ACUACU-GCG-ATT-3'. Transfection of duplex siRNAs was performed with Interferin $^{\mathrm{TM}}$ reagents (PolyPlus Transfection, Ozyme, St Quentin, France), following the manufacturer's instructions. Drug treatment was performed four hours after the transfection, for 96 hours. 


\section{Statistical analysis}

For proteomic analysis, we analyzed our data with the R package Isobar v. 1.14.0 [19] as described above. This statistical analysis allowed the determination of proteins significantly dysregulated by considering a $p$ ValueRatio and a pValueSample $<0.05$. For Cell viability and apoptosis assays, Western blot analysis and siRNA transfection analysis, differences in treatments were compared using the Mann-Whitney $U$-test. Two-sided $p$ values $<0.05$ were considered statistically significant. All analyses were performed using Statview software (Abacus Concept, Berkeley, CA). 


\section{Results}

\section{Identification of 86 differentially expressed proteins upon KDACi and gefitinib co- treatment using iTRAQ-OFFGEL-LC-MS/MS}

A quantitative map of the proteome of mutant KRAS cells treated with KDAC inhibitors and/or gefitinib is a key step to gain a better understanding of the role of proteins in EGFRTKI gefitinib resistance. As it is currently known that the treatment of gefitinib alone does not induce apoptosis in KRAS lung adenocarcinoma, in contrast to the combination of gefitinib with KDAC inhibitors [10][9][11] (a view confirmed in our investigation in Figure S1), we performed our quantitative proteomic analysis based on iTRAQ labeling, as previously described,[18] on H358 cells treated with gefitinib alone or combined with KDAC inhibitors (NAM and TSA). Because proteins may have different roles according to their cellular localization (e.g. some proteins such as EGFR may be localized in both nuclear and cytoplasm with distinct roles), a subcellular fractionation was performed to obtain cytoplasmic and nuclear protein extracts and to have a better description of proteome in nucleus and cytoplasm. The purity of these subcellular extracts was assessed by Western blot analysis (Figure S2). The large-scale quantitative proteomic analysis based on a nLCMALDI-MS/MS strategy resulted in the identification of 1095 unique proteins in the cytoplasm and 288 unique proteins in the nucleus. We quantified 1008 unique proteins in the cytoplasm and 268 unique proteins in the nucleus (Table S1 for nuclear extract and Table S2 for cytoplasmic extract). Proteins from cells treated with gefitinib alone and combined with TSA and NAM were respectively labeled with iTRAQ tags $m / z, 117$ and 121 . Thus, the ratio 121:117 indicated the relative protein abundance in cells treated with the combination of gefitinib and KDAC inhibitors (TSA and NAM) versus cells treated with the gefitinib only. $P$ value ratio and $p$-value sample both below 0.05 were considered significant. Applying these criteria, we identified 71 and 15 proteins significantly dysregulated depending on treatment in 
the cytoplasm and the nucleus, respectively (Table 1 and Figure 1). In the cytoplasm 36 proteins were downregulated and 35 were upregulated after the combination treatment. In the nucleus, 6 proteins were downregulated and 9 upregulated.

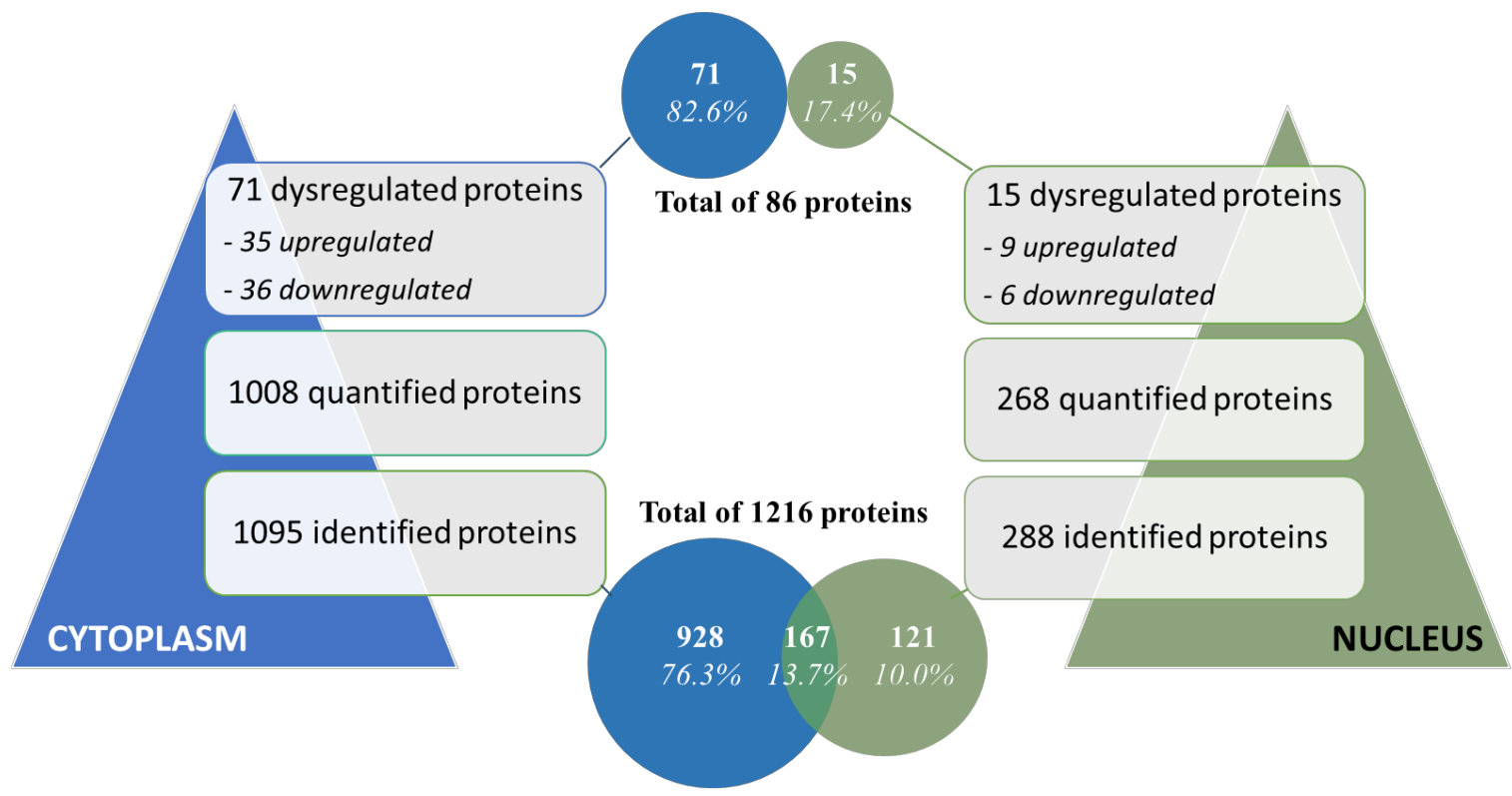

Figure 1. The number of identified, quantified and dysregulated proteins in the nucleus and in the cytoplasm (cells were treated with $0.5 \mu \mathrm{mol} / \mathrm{L}$ gefitinib, $200 \mathrm{ng} / \mathrm{mL}$ trichostatin A and $5 \mathrm{mmol} / \mathrm{L}$ nicotinamide combination versus gefitinib only). Venn diagrams showing the identified/quantified proteins according to their localization in the nucleus and/or in the cytoplasm.

Table 1: List of human proteins significantly dysregulated in gefitinib, TSA and NAM versus gefitinib treated cells (iTRAQ ratio 121/117). Statistically significant iTRAQ ratios ( $p$-value ratio and $p$-value sample $\leq 0.05$ ) for the 86 proteins that are dysregulated in the nuclear and the cytoplasmic extracts.

\begin{tabular}{|c|c|c|c|c|c|}
\hline $\begin{array}{l}\text { GENE } \\
\text { SYMBOL }\end{array}$ & $\begin{array}{l}\text { ACCESSION } \\
\text { NUMIBER }\end{array}$ & $\begin{array}{l}\text { PROTEIN } \\
\text { NAMIES }\end{array}$ & $\begin{array}{l}\text { ITRAQ } \\
\text { RATIO }\end{array}$ & $\begin{array}{c}\text { P-VALUE } \\
\text { RATIO }\end{array}$ & $\begin{array}{l}\text { P-VALUE } \\
\text { SAMIPLE }\end{array}$ \\
\hline \multicolumn{6}{|c|}{ CYTOPLASMIC EXTRACT } \\
\hline NCKAP1 & Q9Y2A7 & Nck-associated protein 1 (NAP 1) & 0.24 & $1.13 \times 10^{-02}$ & $1.49 \times 10^{-13}$ \\
\hline $\mathrm{TF}$ & P02787 & Serotransferrin(Transferrin) & 0.28 & $1.09 \times 10^{-02}$ & $4.77 \times 10^{-11}$ \\
\hline ITPA & Q9BY32 & Inosine triphosphate pyrophosphatase & 0.34 & $2.66 \times 10^{-02}$ & $1.01 \times 10^{-08}$ \\
\hline DPYSL2 & Q16555 & Dihydropyrimidinase-related protein 2 & 0.35 & $1.46 \times 10^{-02}$ & $2.66 \times 10^{-08}$ \\
\hline SNX6 & Q9UNH7 & Sorting nexin-6(TRAF4-associated factor 2 ) & 0.38 & $8.36 \times 10^{-03}$ & $3.73 \times 10^{-07}$ \\
\hline LPP & Q93052 & Lipoma-preferred partner & 0.38 & $3.35 \times 10^{-02}$ & $3.76 \times 10^{-07}$ \\
\hline RSG1 & Q9BU20 & REM2-and Rab-like small GTPase 1 & 0.38 & $3.48 \times 10^{-05}$ & $4.77 \times 10^{-07}$ \\
\hline MYO18A & Q92614 & Unconventional myosin-XVIIIa & 0.41 & $2.84 \times 10^{-02}$ & $2.23 \times 10^{-06}$ \\
\hline S100P & $\mathrm{P} 25815$ & Protein S100-P & 0.43 & $5.51 \times 10^{-03}$ & $7.34 \times 10^{-06}$ \\
\hline RPL13A & $\mathrm{P} 40429$ & 60 S ribosomal protein $\mathrm{L} 13 \mathrm{a}$ & 0.43 & $4.62 \times 10^{-02}$ & $7.54 \times 10^{-06}$ \\
\hline PAICS & P22234 & Multifunctional protein ADE2 & 0.44 & $2.03 \times 10^{-02}$ & $1.11 \times 10^{-05}$ \\
\hline DLGAP5 & Q15398 & Disks large-associated protein 5 (DAP-5) & 0.45 & $1.52 \times 10^{-02}$ & $2.40 \times 10^{-05}$ \\
\hline RPS15 & P62841 & 40S ribosomal protein $\mathrm{S} 15$ (RIG protein) & 0.47 & $3.76 \times 10^{-02}$ & $5.34 \times 10^{-05}$ \\
\hline AARS & P49588 & Alanine-tRNA ligase, cytoplasmic & 0.48 & $3.22 \times 10^{-05}$ & $6.79 \times 10^{-05}$ \\
\hline PRMT5 & O14744 & Protein arginine N-methyltransferase 5 & 0.50 & $4.89 \times 10^{-02}$ & $1.58 \times 10^{-04}$ \\
\hline BLVRB & P30043 & Flavin reductase(NADPH) & 0.53 & $1.38 \times 10^{-04}$ & $5.04 \times 10^{-04}$ \\
\hline IPO5 & 000410 & Importin-5 (Imp5) & 0.55 & $3.98 \times 10^{-05}$ & $9.55 \times 10^{-04}$ \\
\hline UBE2V2 & Q15819 & Ubiquitin-conjugating enzyme $\mathrm{E} 2$ variant 2 & 0.55 & $4.52 \times 10^{-02}$ & $1.17 \times 10^{-03}$ \\
\hline MAP4 & P27816 & Microtubule-associated protein 4 & 0.56 & $1.61 \times 10^{-06}$ & $1.56 \times 10^{-03}$ \\
\hline
\end{tabular}




\begin{tabular}{|c|c|c|c|c|c|}
\hline CAB39 & Q9Y376 & Calcium-binding protein 39 (MO25alpha) & 0.56 & $6.47 \times 10^{-05}$ & $1.65 \times 10^{-13}$ \\
\hline EEF1A2 & Q05639 & $\begin{array}{l}\text { Elongation factor 1-alpha } 2 \text { (Eukaryotic elongation factor } \\
1 \mathrm{~A}-2)(\mathrm{eEF} 1 \mathrm{~A}-2)\end{array}$ & 0.57 & $4.09 \times 10^{-12}$ & $1.93 \times 10^{-13}$ \\
\hline GART & P22102 & Trifunctional purine biosynthetic protein adenosine-3 & 0.57 & $9.54 \times 10^{-13}$ & $2.12 \times 10^{-13}$ \\
\hline TARS & P26639 & Threonine-tRNA ligase, cytoplasmic & 0.58 & $8.90 \times 10^{-05}$ & $2.61 \times 10^{-13}$ \\
\hline UBE2N & P61088 & Ubiquitin-conjugating enzyme $\mathrm{E} 2 \mathrm{~N}$ & 0.59 & $2.97 \times 10^{-12}$ & $3.80 \times 10^{-13}$ \\
\hline CCT7 & Q99832 & T-complex protein 1 subunit eta & 0.61 & $3.99 \times 10^{-04}$ & $5.31 \times 10^{-13}$ \\
\hline UGDH & O60701 & UDP-glucose 6-dehydrogenase & 0.63 & $2.31 \times 10^{-02}$ & $9.19 \times 10^{-13}$ \\
\hline STAT1 & P42224 & $\begin{array}{l}\text { Signal transducer and activator of transcription 1- } \\
\text { alpha/beta(STAT1) }\end{array}$ & 0.65 & $7.42 \times 10^{-13}$ & $1.42 \times 10^{-12}$ \\
\hline ECI1 & P42126 & Enoyl-CoA delta isomerase 1, mitochondrial & 0.66 & $1.97 \times 10^{-13}$ & $1.56 \times 10^{-12}$ \\
\hline RPS3 & P23396 & $40 \mathrm{~S}$ ribosomal protein $\mathrm{S} 3$ & 0.68 & $7.78 \times 10^{-13}$ & $2.25 \times 10^{-12}$ \\
\hline C9orf64 & Q5T6V5 & UPF0553 protein C9orf64 & 0.68 & $1.07 \times 10^{-12}$ & $2.44 \times 10^{-12}$ \\
\hline WARS & P23381 & Tryptophan-tRNA ligase, cytoplasmic & 0.68 & $1.05 \times 10^{-02}$ & $2.48 \times 10^{-02}$ \\
\hline EIF5A & P63241 & Eukaryotic translation initiation factor 5A-1 (eIF-5A-1) & 0.68 & $2.35 \times 10^{-13}$ & $2.49 \times 10^{-12}$ \\
\hline EIF1AX & P47813 & $\begin{array}{l}\text { Eukaryotic translation initiation factor } 1 \mathrm{~A}, \mathrm{X}- \\
\text { chromosomal (eIF-1AX isoform) }\end{array}$ & 0.68 & $1.13 \times 10^{-12}$ & $2.53 \times 10^{-12}$ \\
\hline S100A6 & P06703 & Protein S100-A6(Calcyclin) & 0.69 & $1.78 \times 10^{-02}$ & $2.96 \times 10^{-12}$ \\
\hline IQGAP1 & P46940 & Ras GTPase-activating-like protein IQGAP1 (p195) & 0.69 & $3.47 \times 10^{-02}$ & $2.98 \times 10^{-12}$ \\
\hline SERBP1 & Q8NC51 & Plasminogen activator inhibitor 1 RNA-binding protein & 0.70 & $1.74 \times 10^{-12}$ & $3.31 \times 10^{-12}$ \\
\hline PPA2 & Q9H2U2 & Inorganic pyrophosphatase 2 , mitochondrial & 1.44 & $1.14 \times 10^{-02}$ & $3.00 \times 10^{-02}$ \\
\hline TACSTD2 & P09758 & Tumor-associated calcium signal transducer 2 & 1.53 & $1.50 \times 10^{-12}$ & $1.44 \times 10^{-22}$ \\
\hline STOML2 & Q9UJZ1 & Stomatin-like protein 2, mitochondrial & 1.60 & $2.62 \times 10^{-12}$ & $7.77 \times 10^{-03}$ \\
\hline GAA & P10253 & Lysosomal alpha-glucosidase & 1.63 & $2.41 \times 10^{-13}$ & $6.16 \times 10^{-13}$ \\
\hline HNRNPK & P61978 & Heterogeneous nuclear ribonucleoprotein K (hnRNPK) & 1.65 & $3.67 \times 10^{-12}$ & $4.98 \times 10^{-13}$ \\
\hline DHRS2 & Q13268 & $\begin{array}{l}\text { Dehydrogenase/reductase SDR family member } 2 \text {, } \\
\text { mitochondrial }\end{array}$ & 1.73 & $3.93 \times 10^{-12}$ & $2.38 \times 10^{-13}$ \\
\hline TMED10 & P49755 & Transmembrane emp24 domain-containing protein 10 & 1.76 & $2.90 \times 10^{-12}$ & $1.86 \times 10^{-13}$ \\
\hline IDH1 & O75874 & Isocitrate dehydrogenase [NADP] cytoplasmic (IDH) & 1.78 & $2.23 \times 10^{-13}$ & $1.61 \times 10^{-03}$ \\
\hline SCARB2 & Q14108 & $\begin{array}{l}\text { Lysosome membrane protein } 2 \text { ( } 85 \mathrm{kDa} \text { lysosomal } \\
\text { membrane sialoglycoprotein) }\end{array}$ & 1.87 & $2.86 \times 10^{-12}$ & $6.92 \times 10^{-04}$ \\
\hline ACOT9 & Q9Y305 & Acyl-coenzyme A thioesterase 9, mitochondrial & 1.95 & $4.33 \times 10^{-12}$ & $3.18 \times 10^{-04}$ \\
\hline F11R & Q9Y624 & Junctional adhesion molecule A & 2.00 & $4.30 \times 10^{-12}$ & $1.96 \times 10^{-04}$ \\
\hline PREP & P48147 & Prolyl endopeptidase & 2.00 & $3.06 \times 10^{-12}$ & $1.93 \times 10^{-04}$ \\
\hline GCN1 & Q92616 & Translational activator GCN1 & 2.02 & $3.53 \times 10^{-12}$ & $1.55 \times 10^{-04}$ \\
\hline PPP1R7 & Q15435 & Protein phosphatase 1 regulatory subunit 7 & 2.17 & $3.02 \times 10^{-12}$ & $3.47 \times 10^{-05}$ \\
\hline GNL1 & P36915 & $\begin{array}{l}\text { Guanine nucleotide-binding protein-like } 1 \text { (GTP-binding } \\
\text { protein HSR1) }\end{array}$ & 2.36 & $4.99 \times 10^{-12}$ & $5.50 \times 10^{-16}$ \\
\hline NMRAL1 & Q9HBL8 & NmrA-like family domain-containing protein 1 & 2.44 & $4.43 \times 10^{-12}$ & $2.38 \times 10^{-66}$ \\
\hline TECR & Q9NZ01 & Very-long-chain enoyl-CoA reductase & 2.51 & $3.87 \times 10^{-12}$ & $1.14 \times 10^{-06}$ \\
\hline PROSC & O94903 & $\begin{array}{l}\text { Proline synthase co-transcribed bacterial homolog } \\
\text { protein }\end{array}$ & 2.61 & $4.25 \times 10^{-12}$ & $4.20 \times 10^{-07}$ \\
\hline RABL6 & Q3YEC7 & Rab-like protein 6(GTP-binding protein Parf) & 2.62 & $3.20 \times 10^{-12}$ & $3.97 \times 10^{-07}$ \\
\hline TIMM50 & Q3ZCQ8 & $\begin{array}{l}\text { Mitochondrial import inner membrane translocase } \\
\text { subunit TIM50 }\end{array}$ & 2.64 & $1.56 \times 10^{-12}$ & $3.32 \times 10^{-07}$ \\
\hline DPM1 & O60762 & Dolichol-phosphate mannosyltransferase subunit 1 & 2.67 & $4.46 \times 10^{-12}$ & $2.32 \times 10^{-07}$ \\
\hline CARS & P49589 & Cysteine-tRNA ligase, cytoplasmic & 2.68 & $2.56 \times 10^{-12}$ & $2.21 \times 10^{-07}$ \\
\hline PDP1 & Q9P0J1 & $\begin{array}{l}\text { [Pyruvate dehydrogenase [acetyl-transferring]]- } \\
\text { phosphatase 1, mitochondrial(PDP 1) }\end{array}$ & 2.68 & $3.91 \times 10^{-12}$ & $2.09 \times 10^{-07}$ \\
\hline TBCA & O75347 & Tubulin-specific chaperone A & 2.77 & $2.32 \times 10^{-12}$ & $8.43 \times 10^{-18}$ \\
\hline HSPA2 & P54652 & Heat shock-related $70 \mathrm{kDa}$ protein 2 & 2.98 & $2.66 \times 10^{-12}$ & $1.08 \times 10^{-08}$ \\
\hline UBXN7 & O94888 & UBX domain-containing protein 7 & 3.02 & $2.63 \times 10^{-12}$ & $7.04 \times 10^{-99}$ \\
\hline EIF3M & Q7L2H7 & $\begin{array}{l}\text { Eukaryotic translation initiation factor } 3 \text { subunit } \mathrm{M} \\
(\mathrm{eIF} 3 \mathrm{~m})\end{array}$ & 3.17 & $3.84 \times 10^{-12}$ & $1.70 \times 10^{-99}$ \\
\hline CRIP2 & P52943 & Cysteine-rich protein 2(CRP-2) (Protein ESP1) & 3.21 & $4.93 \times 10^{-02}$ & $1.13 \times 10^{-99}$ \\
\hline VAPA & Q9P0L0 & $\begin{array}{l}\text { Vesicle-associated membrane protein-associated protein } \\
\text { A }\end{array}$ & 3.21 & $1.84 \times 10^{-12}$ & $1.06 \times 10^{-09}$ \\
\hline EXOC4 & Q96A65 & Exocyst complex component 4 & 3.31 & $2.90 \times 10^{-12}$ & $4.15 \times 10^{-10}$ \\
\hline AP2B1 & P63010 & AP-2 complex subunit beta (AP105B) & 3.70 & $1.68 \times 10^{-12}$ & $9.43 \times 10^{-12}$ \\
\hline UCHL5 & Q9Y5K5 & Ubiquitin carboxyl-terminal hydrolase isozyme L5 & 3.92 & $2.36 \times 10^{-12}$ & $1.24 \times 10^{-12}$ \\
\hline
\end{tabular}




\begin{tabular}{|c|c|c|c|c|c|}
\hline PRKRA & O75569 & $\begin{array}{l}\text { (UCH-L5) } \\
\text { Interferon-inducible double-stranded RNA-dependent } \\
\text { protein kinase activator A }\end{array}$ & 4.28 & $1.32 \times 10^{-02}$ & $4.46 \times 10^{-14}$ \\
\hline KRT6B & P04259 & Keratin, type II cytoskeletal 6B & 5.31 & $1.46 \times 10^{-02}$ & $5.41 \times 10^{-18}$ \\
\hline FLII & Q13045 & Protein flightless-1 homolog & 7.05 & $4.22 \times 10^{-03}$ & $6.14 \times 10^{-24}$ \\
\hline \multicolumn{6}{|c|}{ NUCLEAR EXTRACT } \\
\hline CKAP4 & Q07065 & Cytoskeleton-associated protein 4 (P63; CKAP4) & 0.24 & $1.90 \times 10^{-02}$ & $1.22 \times 10^{-13}$ \\
\hline ENO1 & P06733 & Alpha-enolase & 0.50 & $1.07 \times 10^{-02}$ & $2.13 \times 10^{-04}$ \\
\hline ACTN1 & P12814 & Alpha-actinin-1 & 0.52 & $3.64 \times 10^{-04}$ & $3.91 \times 10^{-04}$ \\
\hline SLC3A2 & P08195 & 4F2 cell-surface antigen heavy chain & 0.53 & $9.57 \times 10^{-06}$ & $6.19 \times 10^{-04}$ \\
\hline API5 & Q9BZ75 & Apoptosis inhibitor 5 & 0.62 & $2.51 \times 10^{-03}$ & $7.34 \times 10^{-03}$ \\
\hline HSPE1 & P61604 & $10 \mathrm{kDa}$ heat shock protein, mitochondrial (Hsp10) & 0.71 & $1.15 \times 10^{-02}$ & $4.18 \times 10^{-02}$ \\
\hline SF3B3 & Q15393 & Splicing factor $3 \mathrm{~B}$ subunit 3 & 1.43 & $4.69 \times 10^{-02}$ & $3.18 \times 10^{-02}$ \\
\hline RAN & P62826 & GTP-binding nuclear protein Ran & 1.45 & $5.10 \times 10^{-03}$ & $2.89 \times 10^{-02}$ \\
\hline ERH & P84090 & Enhancer of rudimentary homolog & 1.46 & $1.91 \times 10^{-02}$ & $2.58 \times 10^{-02}$ \\
\hline RPN2 & $\mathrm{P} 04844$ & $\begin{array}{l}\text { Dolichyl-diphosphooligosaccharide-protein } \\
\text { glycosyltransferase subunit } 2\end{array}$ & 1.52 & $7.22 \times 10^{-03}$ & $1.51 \times 10^{-12}$ \\
\hline PRMT1 & Q99873 & Protein arginine N-methyltransferase 1 & 1.56 & $1.01 \times 10^{-02}$ & $1.07 \times 10^{-02}$ \\
\hline MATR3 & P43243 & Matrin-3 & 1.59 & $1.45 \times 10^{-02}$ & $8.24 \times 10^{-03}$ \\
\hline ATAD3A & Q9NVI7 & ATPase family AAA domain-containing protein $3 \mathrm{~A}$ & 1.71 & $1.14 \times 10^{-02}$ & $2.99 \times 10^{-03}$ \\
\hline HIST1H4I & P62805 & Histone H4 & 1.91 & $6.64 \times 10^{-03}$ & $4.45 \times 10^{-04}$ \\
\hline PAQR9 & Q6ZVX9 & Progestin and adipoQ receptor family member 9 & 2.68 & $4.22 \times 10^{-02}$ & $2.06 \times 10^{-07}$ \\
\hline
\end{tabular}

Most of the identified proteins were found only in the cytoplasmic extract (76.3\%) and few only in the nuclear extract $(10.0 \%)$ while $13.7 \%$ of proteins were found in the two compartments (Figure 1). Similarly, most of the dysregulated proteins were found in the cytoplasm extract $(82.6 \%)$ and few in the nuclear extract (17.4\%). Interestingly, no protein was found dysregulated in both compartments.

\section{Functional analysis of datasets: Gene ontology, pathway and network analyses}

We then performed bioinformatics analysis with the 86 proteins dysregulated in the nucleus or the cytoplasm using Panther.[22] The classification of the dysregulated proteins into the following gene ontology and PANTHER categories: Protein Family; Protein class; Molecular function; Biological process; Cellular Component and Pathway, is listed in Table S3. A summary of this functional classification regarding biological processes and molecular functions is graphically illustrated in Figure 2. Dysregulated proteins, when KDACi (TSA and 
NAM) restored the sensitivity to gefitinib were mainly involved in the following biological processes: metabolism $(32.1 \%)$ including primary metabolic process, nitrogen compound metabolic process, biosynthetic process; cellular process $(28.8 \%)$ including cell cycle, cell communication, cellular component movement, chromosome segregation; cellular component organization and biogenesis (17\%), localization (6.0\%), development process $(3.8 \%)$ including cell death related to apoptosis, system development, cell differentiation; and response to stimulus (3.3\%) (Figure 2A). Concerning molecular functions, dysregulated proteins belonged to the main following categories: binding involving nucleic acid, proteins, chromatins, calcium ions or lipids (44\%); catalytic activity of hydrolases, ligases, oxidoreductases, transferases, enzyme regulators (38.1\%); structural molecule activity of cytoskeleton and ribosome (10.3\%), receptor activity $(3.1 \%)$ and translation regular activity (2.1\%) (Figure 2B).
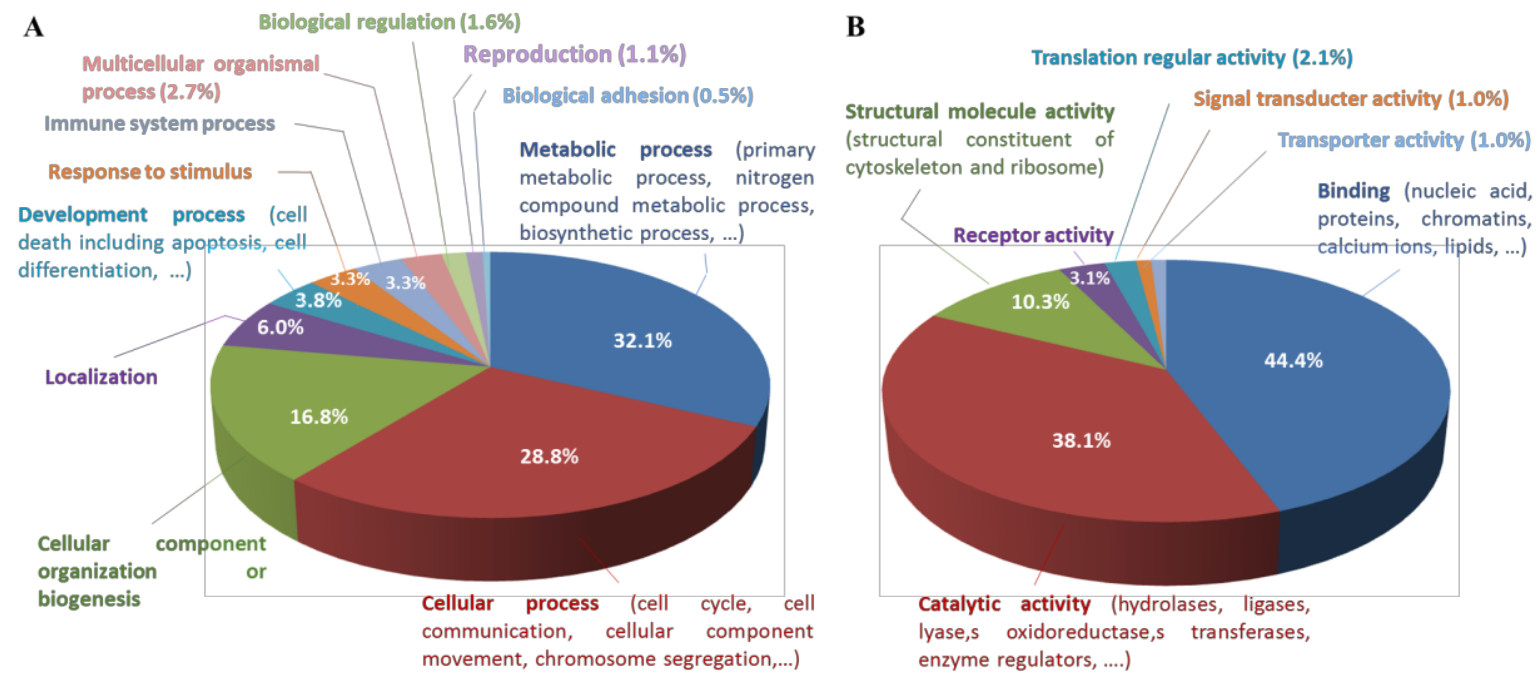

Figure 2. Functional distribution of the 86 proteins identified as dysregulated in the nucleus and in the cytoplasm when treated with gefitinib, trichostatin $A$ and nicotinamide combination versus gefitinib only according to biological processes (A), and molecular functions (B) categories. Assignment were made with PANTHER tool. The numbers in brackets correspond to the percentage of identified proteins classified in the category. If a protein is classified into 2 ontology terms that are not parent or child to each other, it counts in the 2 classes.

Pathway enrichment analysis was performed using PathVisio[23] and the top enriched pathways are listed in Table 2. As expected, histone modification was the top enriched 
pathway. Several other pathways related to transcription and metabolism such as microRNA (miRNA) biogenesis and glutathione metabolism were also enriched.

Table 2. List of top enriched pathways provided after over-representation analysis with PathVisio.

\begin{tabular}{|c|c|c|c|c|c|c|}
\hline \multicolumn{7}{|l|}{ PATHWAY ANALYSIS } \\
\hline Pathway Name & $\begin{array}{c}\text { Positive } \\
\text { (r) }\end{array}$ & $\begin{array}{l}\text { Measured } \\
\text { (n) }\end{array}$ & Total & $\%$ & Z Score & $\begin{array}{c}\text { p-value } \\
\text { (permuted) }\end{array}$ \\
\hline Histone Modifications* & 11 & 12 & 69 & 91.67 & 16.68 & $<0.001$ \\
\hline miRNA Biogenesis* & 1 & 1 & 8 & 100.00 & 5.23 & $<0.001$ \\
\hline Glutathione Metabolism* & 1 & 4 & 57 & 25.00 & 2.33 & 0.024 \\
\hline mRNA Processing & 4 & 47 & 130 & 8.51 & 1.91 & 0.048 \\
\hline
\end{tabular}

Positive ( $r$ ) is the number of genes in the pathway significantly dysregulated

Measured $(n)$ is the number of genes in the pathway measured in the experiment

Total is the total number of elements in the pathway

$\%$ is the percentage of genes dysregulated regarding to all genes measured in the pathway

$Z$-Score is the score calculated for over-representation analysis. Pathways with a high Z-Score have more significantly up- or down-regulated genes than expected.

The enrichment is significant for a p-value $<0.005$

*Only pathways with a Z-Score of $>1.96$ and a p-value of $<0.05$ were considered significantly affected [24]

We finally performed network analysis with PathwayStudio and generated a sub-network with centers downstream of the dysregulated proteins to evaluate the potential connections between these dysregulated proteins and biological processes. Upstream neighbors (entities directly connected to the other entity / entities selected on the network) diagram of apoptosis were in the top sub-network and contained the most proteins from the list imported for the analysis (Table 3). Indeed, 57 out of 86 proteins from the input list were known to be connected to apoptosis (Figure 3). Twenty-nine proteins were upregulated when KDACi restored sensitivity to gefitinib and 28 proteins were downregulated. Proteins such as STAT1 and eEF1A2 known to negatively regulate apoptosis were downregulated when KDACi restored the sensitivity to gefitinib and prompted our further investigations that are described below. 
Table 3. List of sub-networks provided after network analysis with PathwayStudio.

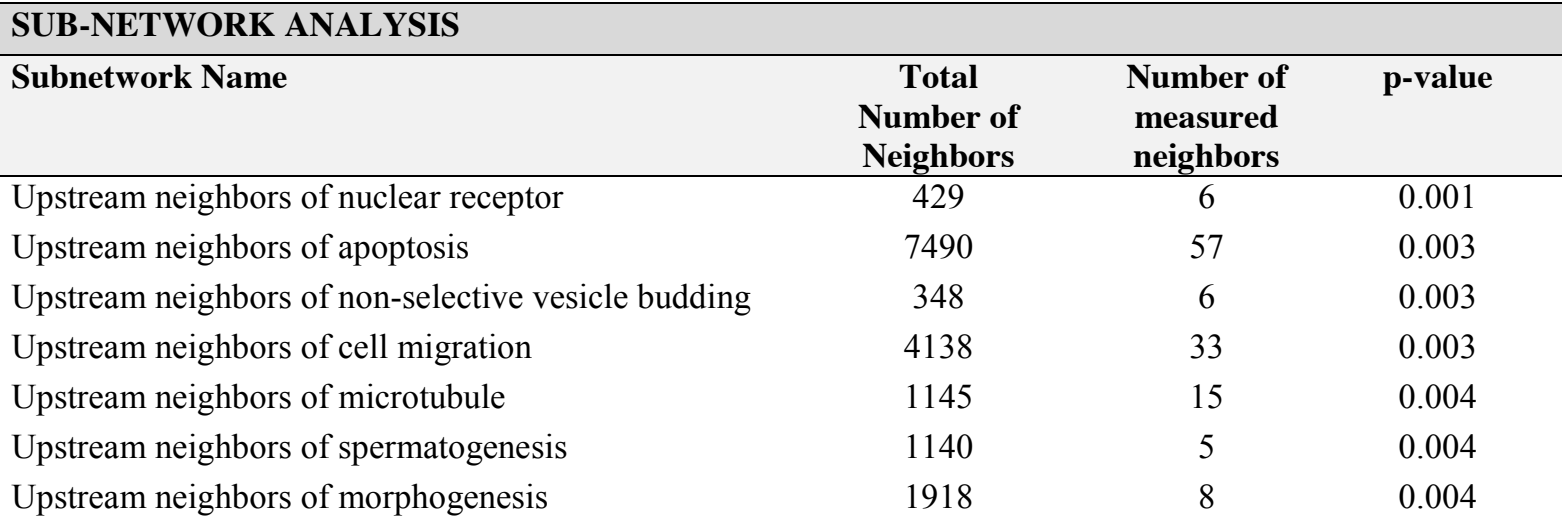

Total number of Neighbors is the number of entities inside the network directly connected to the measured proteins

Number of measured neighbors is the number of proteins measured that are part of the sub-network

The sub-network is significant for a p-value $<0.005$ 


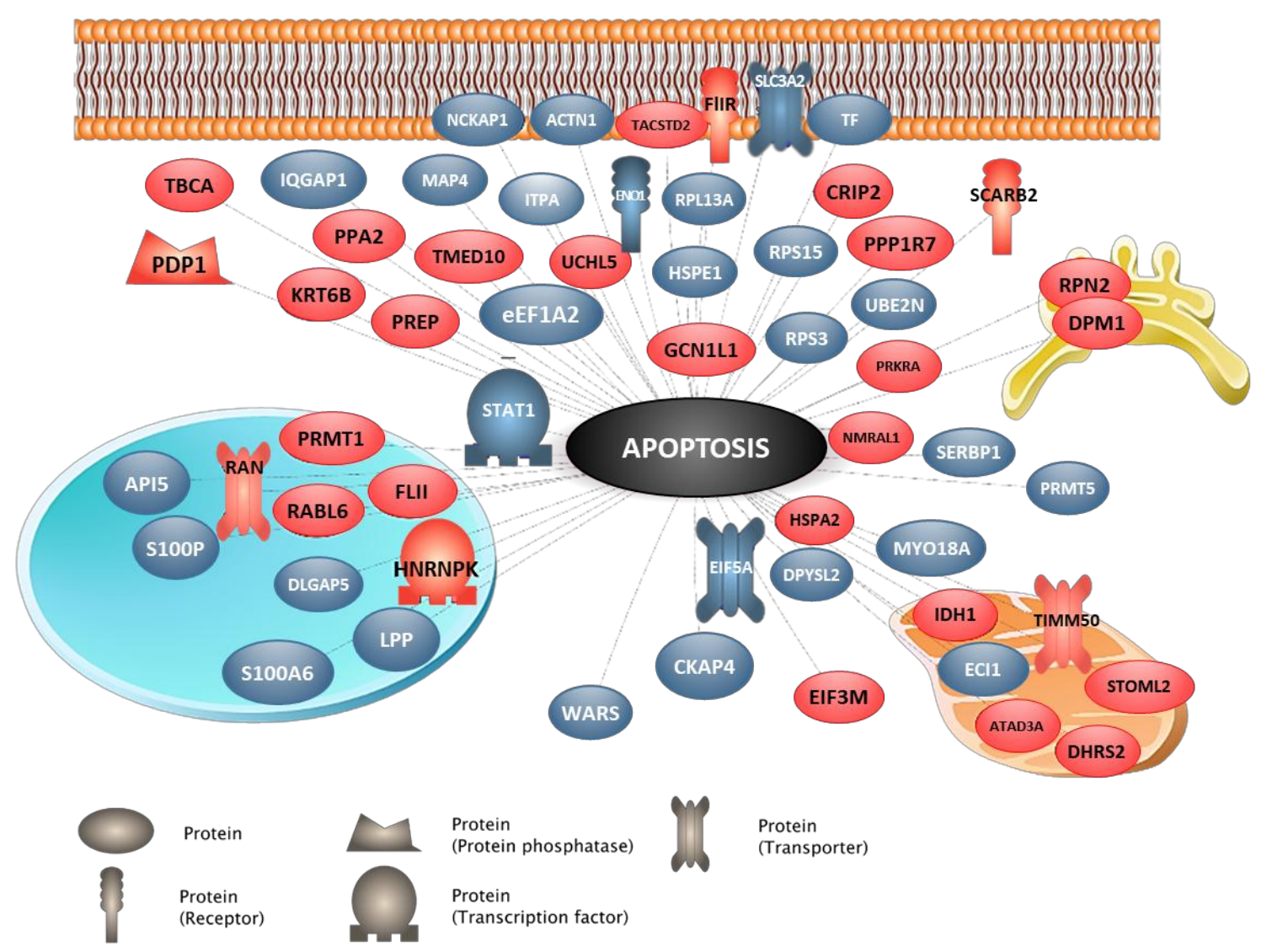

Figure 3. Upstream neighbors of apoptosis for the 57 proteins reported as directly related to this process by the subnetwork analysis of the 86 dysregulated proteins in the nucleus and in the cytoplasm when treated with gefitinib, trichostatin $A$ and nicotinamide combination versus gefitinib only. Proteins in red are upregulated (29) and those in blue are downregulated (28). The function of the protein is also represented as seen in the legend, and the link between the proteins and apoptosis is representing the regulation.

\section{Validation of selected dysregulated proteins by Western blot analysis}

The differential expression levels of the proteins identified by iTRAQ approach were validated using Western blot analysis on three proteins. As our study aimed to determine if the restoration of sensitivity to gefinitib by KDACi treatment may be related to a lower expression of proteins that are involved in viability of NSCLC and especially in negative effect of apoptosis, we selected three proteins that were significantly down-regulated by gefitinib/KDAC inhibitors treatment and known for their negative effect on apoptosis. Therefore, Western blot analysis was conducted on STAT1 and eEF1A2 proteins in cytoplasm extract (STAT1 cytoplasmic protein, P42224, iTRAQ ratio: 0.65, p-value ratio: $7.42 \times 10^{-03}, \mathrm{p}$-value sample : $1.42 \times 10^{-02}$ and eEF1A2 cytoplasmic protein (Q05639, iTRAQ 
ratio: 0.57 , p-value ratio: $4.09 \times 10^{-02}$, p-value sample $: 1.93 \times 10^{-03}$ ). We also performed Western blot analysis on P63 protein in nuclear extract (P63, CKAP4, Q07065, Cytoskeletonassociated protein 4, iTRAQ ratio: 0.24 , p-value ratio: $1.90 \times 10^{-02}$, p-value sample: $1.22 \times 10^{-}$ ${ }^{13}$. Western blot analyses for STAT1, eEF1A2 and P63 protein expressions were performed on nuclear and cytoplasmic extracts of H358 cells treated with KDAC inhibitors (TSA and NAM) and/or gefitinib (Figure 4A). As expected, STAT1 and eEF1A2 were localized in the cytoplasm, and P63 in the nucleus. Compared to control or gefitinib-treated cells, eEF1A2 expression was significantly decreased in the presence of TSA/NAM KDAC inhibitors (Figure 4A and 4B). In response to KDAC inhibitors and gefitinib combination treatment, eEF1A2 expression was downregulated by $78 \%$ compared to control or gefitinib alone. Compared to the control, P63 expression level was slightly upregulated after gefitinib or KDAC inhibitors treatments, but strongly downregulated by the combination treatment $(67 \%$ of decreased signal). STAT1 immunoblots showed two naturally spliced forms: STAT1- $\alpha$ and STAT1- $\beta .[25]$ Interestingly, we observed that only STAT1- $\beta$ expression level was upregulated after gefitinib or KDAC inhibitors treatments, and strongly downregulated by the combination treatment ( $70 \%$ of decreased signal compared to the control). STAT1- $\alpha$ expression did not change whatever the treatment. These results provided immunological validation of the eEF1A2, P63, and STAT1 protein dysregulations evidenced by our iTRAQ proteomic results. 
A

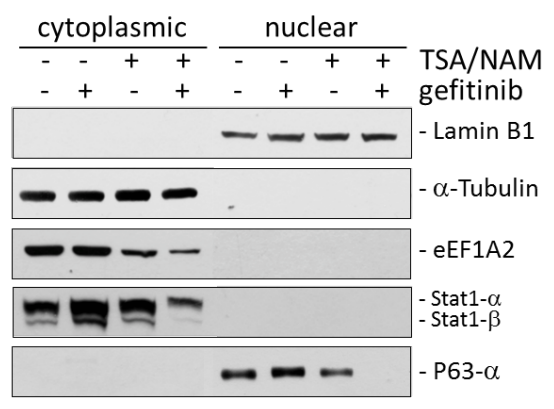

B
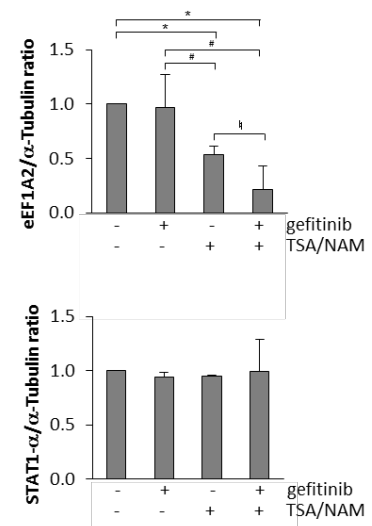
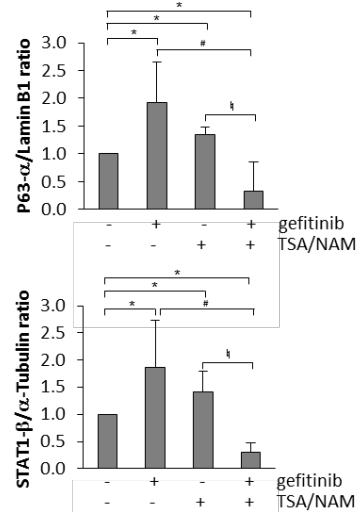

Figure 4. (A) Representative western blot analysis on nuclear and cytoplasmic extracts of $\mathbf{H 3 5 8}$ cells treated with $200 \mathrm{ng} / \mathrm{mL}$ trichostatin $A$ and $5 \mathrm{mmol} / \mathrm{L}$ nicotinamide (TSA/NAM) and/or 0.5 $\mu \mathrm{mol} / \mathrm{L}$ gefitinib as indicated for 96h for STAT1, P63 and eEF1A2. Lamin B1 and a-tubulin were used as nuclear and cytoplasmic loading control, respectively. (B) Quantification of cytoplasmic eEF1A2, STAT1-a and STAT1-b, and nuclear p63-a protein levels was performed as described in the methods sections $(\mathbf{n}=\mathbf{3}) .{ }^{*} \mathrm{p}<0.05$ for comparison between treated and control; ${ }^{*} \mathrm{p}<0.05$ for comparison between treated and gefitinib; ${ }^{\natural} \mathrm{p}<0.05$ for comparison between treated and TSA/NAM.

\section{Do eEF1A2 and STAT1 have a role in resistance to gefitinib?}

Our results described above showed that both eEF1A2 and STAT1 were strongly downregulated with the KDAC inhibitors and gefitinib combination treatment that restored apoptosis. Both eEF1A2 and STAT1 are known to be negative regulators of apoptosis.[26]'[27] This suggested a role of these proteins in the resistance to gefitinib. Therefore, we invalidated eEF1A2 or STAT1 expression with specific siRNAs and evaluated the impact on resistance to gefitinib (Figure 5). A partial downregulation of eEF1A2, and a strong inhibition of both STAT1- $\alpha$ and STAT1- $\beta$ protein level were achieved by siRNA transfection as visualized by Western blot (Figure 5A). As previously observed,[10]'[11] gefitinib induced AKT activation. Surprisingly, we observed a strong increase in gefitinibinduced AKT activation in the presence of eEF1A2 or STAT1 siRNA (Figure 5A). A slight but significant reduction of cell viability was observed in the presence of eEF1A2 siRNA and gefitinib, compared to control siRNAs and gefitinib (Figure 5B). This effect was not observed with STAT1 siRNAs. According to the activated AKT level, we did not observe induction of 
apoptosis after siRNA transfection, as shown by flow cytometry analysis of cleaved caspase-3

(Figure 5C).

A

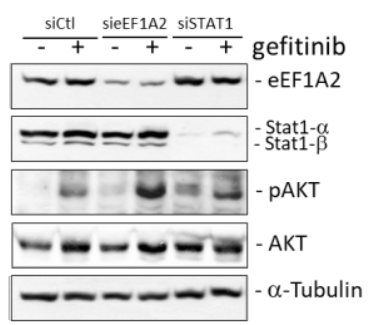

B

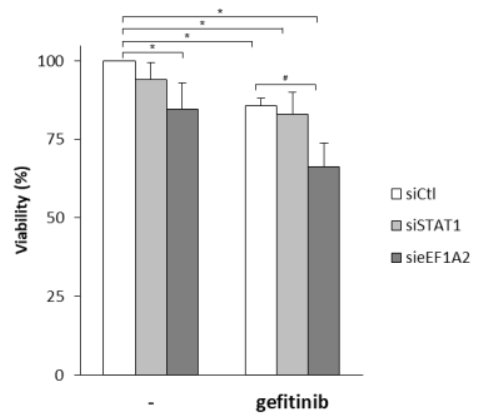

C

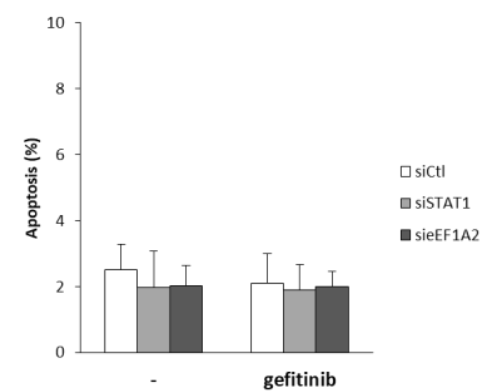

Figure 5. Effects of eEF1A2 and STAT1 silencing on AKT activation, cell viability and apoptosis. H358 cells were transfected with control siRNA (siCtl), eEF1A2 siRNA (sieEF1A2), or STAT1 siRNAs (siSTAT1) and treated with $0.5 \mu \mathrm{mol} / \mathrm{L}$ gefitinib. A: Representative immunoblots of eEF1A2, STAT1 and phosphorylated AKT (pAKT) in cells treated as indicated. a-tubulin was used as a protein level control. B: Cell viability in cells treated as indicated $(\mathbf{n}=\mathbf{3})$. ${ }^{*} \mathrm{p}<0.05$ for comparison between treated and control; ${ }^{*} \mathrm{p}<0.05$ for comparison between treated and gefitinib. C: Apoptosis was measured by flow cytometry analysis of active caspase-3 in cells treated as indicated $(n=3)$.

\section{Discussion}

In this study, we used subcellular fractionation followed by an iTRAQ quantitative proteomic strategy to identify proteins differentially expressed in the nucleus and the cytoplasm of NSCLC cells after KDAC inhibitors and gefitinib combination treatment compared to the resistant state observed after gefitinib treatment alone. We quantified 1008 and 268 unique proteins in the cytoplasm and in the nucleus, respectively. It should be noted that a nLC-ESIMS/MS analysis may lead to a deeper proteome description in terms of protein numbers. But our nLC-MALDI-MS/MS analysis presents several advantages in terms of insensitivity to the presence of ionization suppression agents and use of high resolution mass analyzer such as a TOF/TOF reflector. nLC-MALDI-MS/MS analysis may also limit accuracy quantitation issues in iTRAQ analysis. As nLC-MALDI-MS/MS analysis generates mostly single charge peptide ions, while nLC-ESI-MS/MS favors the formation of double or triple charge ions, the risk of precursor ion overlapping for generating $\mathrm{MS} / \mathrm{MS}$ spectra required for iTRAQ 
quantitation is more limited in nLC-MALDI-MS/MS analysis. Moreover, nLC-MALDIMS/MS is based upon an off-line LC-MS/MS analysis and not on an on-line LC-MS/MS analysis, thus limiting over oversampling. [28-30] According to our nLC-MALDI-MS/MS quantitative approach and after statistical analysis of these 1276 proteins, 71 proteins in the cytoplasm and 15 proteins in the nucleus were differentially expressed in terms of protein level. Among the dysregulated proteins, we selected three proteins involved in cell death and apoptosis regulation to further validate proteomic analysis. The changes in protein expression level of P63, STAT1 and eEF1A2 assessed by Western blot analysis confirmed our results obtained by iTRAQ proteomic analysis. Both eEF1A2 and STAT1 were detected in the cytoplasm, and P63 in the nucleus, which is also consistent with our proteomics results and previous reports in the literature.[26]'[27]'[31] .

Based on the subcellular fractionation (nucleus and cytoplasm) prior to quantitative proteomic analysis, we observed that most of the proteins were found in the cytoplasm and only a minor subset of proteins $(14 \%)$ was found in the two compartments. Similar results have been observed in a previous study[32] that reported subcellular fractionation (cytoplasmic, nuclear and nucleolar fractions) prior to quantitative proteomics in HCT116 cells. They also observed that the proteome was partitioned into specific subcellular locations and that few proteins were equally distributed between two or more compartments. We also observed that the differential response to the combined treatment versus gefitinib treatment alone was specific for each compartment. Among the 86 proteins observed as dysregulated, each dysregulated protein was reported as dysregulated in cytoplasm or nucleus, but never in both compartments. Nevertheless, the degree of response was similar in both compartments with around $6 \%$ and $5 \%$ of proteins differentially expressed in the cytoplasm and the nucleus respectively. 
We used gene ontology analysis to demonstrate the most represented molecular functions reflecting the cell response to the combined $\mathrm{KDACi} /$ gefitinib treatment. Those molecular functions included binding (involving chromatins as expected by KDACi treatment but also nucleic acid, proteins, calcium ions or lipids), catalytic activity, receptor activity of hydrolases, ligases, lyases, oxidoreductases, transferases, enzyme regulators; structural molecule activity of cytoskeleton and ribosome and, finally, signal transduction activity. The biological processes mainly affected by the combined treatment (KDACi and gefitinib) overcoming the resistance to gefitinib were cellular metabolism and cell transcription. This is consistent with our pathway enrichment analysis. While the top enriched pathway is histone modification, as expected using the KDACi treatment, other pathways such as microRNA (miRNA) biogenesis and glutathione metabolism were also enriched. It is now known that miRNAs, well known for regulating gene expression, may act as tumor suppressors. Therefore, alterations in miRNA biogenesis machinery leading to a decrease of the global miRNA were reported as oncogenic in human cancers [33]'[34] including NSCLC.[35] More interestingly, Sin and his co-workers[36] recently reported that miRNA biogenesis is not affected only in human lung cancer, but also in resistance to gefitinib in NSCLC. In this paper, we highlighted that miRNA biogenesis may be also influenced by KDACi treatment for helping to overcome the resistance to gefinitib in H358 NSCLC. Cellular metabolism is already well known to be altered in tumors through metabolism reprogramming of cancer cells, but its implication in resistance is less described. However, alterations of cellular metabolism, especially an enhanced glutamine metabolism, was already known to be related to EGFR-TKI erlotinib resistance in NSCLC.[37] This suggested that a pattern of these cellular metabolism alterations may be considered as a promising biomarker signature to predict the likelihood of patients to respond to EGFR-TKIs. This is in concordance with our data that highlighted also the importance of metabolic adaptation in gefitinib resistance in 
H358 NSCLC. Moreover, in addition to higher glutathione levels observed in patients with non-small cell lung cancers, alterations of glutathione metabolism were reported as one major mechanism of chemoresistance in patients with NSCLC.[38]'[39]

Our subnetwork analysis of the dysregulated proteins demonstrated that they were upstream neighbors of nuclear receptors, apoptosis, non-selective vesicle budding, cell migration and microtubule. The majority of the dysregulated proteins were upstream neighbors of apoptosis (57 proteins/86 proteins). Since the combinatory treatment induced apoptosis, we can assume that some proteins in the list could be targeted candidates to restore the sensitivity to gefitinib. That is the case for downregulated proteins such as STAT1 and eEFA1A2 which are known to negatively regulate the apoptosis.

STAT1 localized in the cytoplasm and transiently imported into the nucleus[26] was observed as downregulated in the cytoplasm after treatment with KDAC inhibitors and gefitinib compared to gefitinib treatment alone. Alternative splicing generates two STAT1 isoforms, the full length STAT1- $\alpha$ and the truncated STAT1- $\beta$. The latter lacks 38 residues in the Cterminal transactivation domain.[26] The peptides we observed using proteomic analyses are common to the both isoforms and cannot discriminate between them. But, these isoforms with a $4.3 \mathrm{kDa}$ difference in molecular weight were successfully separated by Western blot analysis. This allowed us to conclude that the combination drug treatment downregulated specifically the STAT1- $\beta$ isoform. Previous literature reports have not thoroughly addressed STAT1 isoform specificity in carcinogenesis and immunity, although STAT1- $\beta$ is able to drive transcription, albeit delayed and with reduced levels, as compared to STAT1- $\alpha$.[26] Here, we observed that gefitinib treatment significantly enhanced STAT1- $\beta$ expression level, whereas the combination of KDAC inhibitors and gefitinib strongly downregulated STAT1- $\beta$ and induced apoptosis. STAT1 is known to play an important role in promoting apoptotic cell 
death.[40] However, increasing evidence has shown that STAT1 also promotes tumor growth and confers therapy resistance.[41] Interestingly, STAT1 has been shown to be associated with KDACs in cisplatin-resistant ovarian cancer cells and etoposide-resistant human lung cancer cells, suggesting that KDAC inhibitors could promote apoptotic cell death by inhibiting STAT1 tumor promoting functions.[25]'[42],[43] These studies are consistent with our results. However, the invalidation of STAT1 by siRNA failed to restore gefitinib-induced apoptosis, suggesting that STAT1 did not directly manage EGFR-TKI resistance. In addition, our data revealed that STAT1 siRNA enhanced the gefitinib-induced AKT activation. Interestingly, the AKT activation is known to favor gefitinib resistance in tumors with wildtype EGFR.[10] Therefore, our data suggest that STAT1- $\beta$ regulated KDAC-dependent AKT activation in response to gefitinib rather than apoptosis.

The protein elongation factor eEF1A2 is a protein translation factor that is likely to be an important oncogene.[27] eEF1A2 expression is a marker of good prognosis in the breast cancer,[44] whereas high expression of eEF1A2 correlates with increased proliferation and is associated with poor prognosis in lung cancer,[45] ovarian cancer [46]'[47] and pancreatic cancer.[48] eEF1A2 has been reported to be antiapoptotic.[49] It protects the cells from stress-induced apoptosis by downregulation of caspase activation.[50]'[27] Moreover, the overexpression of eEF1A2 was reported to have oncogenic effects in human tumors. For instance, it was reported in multiple myeloma that eEF1A2 favored tumor cell proliferation while it inhibited apoptosis.[51] $\mathrm{Li}$ and his co-workers reported a similar conclusion by showing that a specific inhibition of eEF1A2 expression with siRNA in the human lung adenocarcinoma cell lines suppressed proliferation and induced apoptosis.[45] Moreover, the authors evaluated that plitidepsin, an antitumor agent of marine origin, exerts its antitumor activity by targeting eEF1A2. Accordingly, we observed that KDAC inhibitors and gefitinib 
combination strongly downregulated eEF1A2 while apoptosis was induced, suggesting a protective role of eEF1A2 against gefitinib-induced apoptosis. The invalidation of eEF1A2 by siRNA decreased slightly the cell viability of H358 NSCLC, but it failed to restore gefitinibinduced apoptosis, suggesting that eEF1A2 did not directly manage EGFR-TKI resistance through apoptosis process. Interestingly, we observed that eEF1A2 siRNA strongly enhanced the gefitinib-induced AKT phosphorylation, suggesting that eEF1A2 inhibited AKT activation when KDACi treatments are used to restore apoptosis. The inhibition of AKT leading to an increase of apoptosis is concordant with the fact that AKT activation is known to favor gefitinib resistance in tumors with wild-type EGFR and to prevent apoptosis.[10] Nevertheless, eEF1A2 is usually described as an activator of PI3K/AKT. [52]'[53]

In conclusion, our large-scale proteomic analysis revealed the dysregulation of 86 protein expression that was induced by deacetylase inhibitors and gefitinib combined treatment compared to gefitinib treatment alone. Our data allowed a novel description of proteome dysregulation when apoptosis was restored by deacetylase inhibitors and gefitinib in terms of protein expressions, biological processes, pathways and sub-networks related to apoptosis. It also demonstrated that eEF1A2 and STAT1 did not directly control EGFR-TKI resistance through apoptosis process, but both are related to AKT phosphorylation known to act on apoptosis. Altogether, our data provide new insights into proteome dysregulation when apoptosis was restored by deacetylase inhibitors and gefitinib in H358 KRAS mutated and amphiregulin-overexpressing NSCLC cells. Our data also highlighted that further experiments should be conducted to evaluate the role of these proteins in resistance by considering combinatory effects in terms of protein expression and post-translational modifications (PTMs) such as phosphorylation/acetylation. Indeed, these PTMs are well known to act on protein function and protein stability by modifying biological processes such as apoptosis or 
cell survival through isolated modifications or cross-talk effect. Moreover, it would be interesting to perform in vivo experiments to evaluate if similar proteome dysregulations occur through combination effects of EGFR TKI and KDACi in more translationally relevant tumor models such as patient-derived xenograft. Indeed, we already demonstrated the relevance of gefitinib and KDACi combination in vivo and showed that KDACi vorinostat strongly sensitized NSCLC tumors and hepatocarcinoma (KRAS mutated) to gefitinib[9,11] without exploring the dysregulation of the proteome. Similarly, we also identified the deacetylase-dependent pathway induced in gefitinib resistance in human lung tumors with mutant KRAS.[10]

\section{Acknowledgments}

The authors acknowledge the "Ministère de l'Enseignement supérieur et de la Recherche" from the French Government for the financial support as well the University Grenoble Alpes (UGA, Grenoble, France) for the post-doctoral financial support of Dr. S.G. Lehmann. The authors sincerely thank Pr. Donald Martin, from the SyNaBi team in TIMC-IMAG (UMR 5525) at the Université Grenoble Alpes, for assistance in proof-reading in the manuscript.

\section{References}

[1] J. Ferlay, I. Soerjomataram, R. Dikshit, S. Eser, C. Mathers, M. Rebelo, D.M. Parkin, D. Forman, F. Bray, Cancer incidence and mortality worldwide: sources, methods and major patterns in GLOBOCAN 2012, Int. J. Cancer. 136 (2015) E359-386. doi:10.1002/ijc.29210.

[2] R. Siegel, D. Naishadham, A. Jemal, Cancer statistics, 2012, CA. Cancer J. Clin. 62 (2012) 10-29. doi:10.3322/caac.20138.

[3] W. Brugger, M. Thomas, EGFR-TKI resistant non-small cell lung cancer (NSCLC): new developments and implications for future treatment, Lung Cancer Amst. Neth. 77 (2012) 2-8. doi:10.1016/j.lungcan.2011.12.014.

[4] B. Busser, L. Sancey, V. Josserand, C. Niang, M.C. Favrot, J.-L. Coll, A. Hurbin, Amphiregulin promotes BAX inhibition and resistance to gefitinib in non-small-cell lung cancers, Mol. Ther. J. Am. Soc. Gene Ther. 18 (2010) 528-535. doi:10.1038/mt.2009.226.

[5] A. Hurbin, M. Wislez, B. Busser, M. Antoine, C. Tenaud, N. Rabbe, S. Dufort, F. de Fraipont, D. Moro-Sibilot, J. Cadranel, J.-L. Coll, E. Brambilla, Insulin-like growth factor-1 receptor inhibition overcomes gefitinib resistance in mucinous lung adenocarcinoma, J. Pathol. 225 (2011) 83-95. doi:10.1002/path.2897. 
[6] T. Kosaka, E. Yamaki, A. Mogi, H. Kuwano, Mechanisms of resistance to EGFR TKIs and development of a new generation of drugs in non-small-cell lung cancer, J. Biomed. Biotechnol. 2011 (2011) 165214. doi:10.1155/2011/165214.

[7] J. Wang, B. Wang, H. Chu, Y. Yao, Intrinsic resistance to EGFR tyrosine kinase inhibitors in advanced non-small-cell lung cancer with activating EGFR mutations, OncoTargets Ther. 9 (2016) 3711-3726. doi:10.2147/OTT.S106399.

[8] G. Hrustanovic, B.J. Lee, T.G. Bivona, Mechanisms of resistance to EGFR targeted therapies, Cancer Biol. Ther. 14 (2013) 304-314. doi:10.4161/cbt.23627.

[9] B. Busser, L. Sancey, V. Josserand, C. Niang, S. Khochbin, M.C. Favrot, J.-L. Coll, A. Hurbin, Amphiregulin promotes resistance to gefitinib in nonsmall cell lung cancer cells by regulating Ku70 acetylation, Mol. Ther. J. Am. Soc. Gene Ther. 18 (2010) 536-543. doi: $10.1038 / \mathrm{mt} .2009 .227$.

[10] V. Jeannot, B. Busser, E. Brambilla, M. Wislez, B. Robin, J. Cadranel, J.-L. Coll, A. Hurbin, The PI3K/AKT pathway promotes gefitinib resistance in mutant KRAS lung adenocarcinoma by a deacetylase-dependent mechanism, Int. J. Cancer. 134 (2014) 2560-2571. doi:10.1002/ijc.28594.

[11] V. Jeannot, B. Busser, L. Vanwonterghem, S. Michallet, S. Ferroudj, M. Cokol, J.-L. Coll, M. Ozturk, A. Hurbin, Synergistic activity of vorinostat combined with gefitinib but not with sorafenib in mutant KRAS human non-small cell lung cancers and hepatocarcinoma, OncoTargets Ther. 9 (2016) 6843-6855. doi:10.2147/OTT.S117743.

[12] W.S. Xu, R.B. Parmigiani, P.A. Marks, Histone deacetylase inhibitors: molecular mechanisms of action, Oncogene. 26 (2007) 5541-5552. doi:10.1038/sj.onc.1210620.

[13] L.M. Butler, X. Zhou, W.-S. Xu, H.I. Scher, R.A. Rifkind, P.A. Marks, V.M. Richon, The histone deacetylase inhibitor SAHA arrests cancer cell growth, up-regulates thioredoxin-binding protein-2, and down-regulates thioredoxin, Proc. Natl. Acad. Sci. U. S. A. 99 (2002) 11700-11705. doi:10.1073/pnas.182372299.

[14] T. Sanda, T. Okamoto, Y. Uchida, H. Nakagawa, S. Iida, S. Kayukawa, T. Suzuki, T. Oshizawa, T. Suzuki, N. Miyata, R. Ueda, Proteome analyses of the growth inhibitory effects of NCH-51, a novel histone deacetylase inhibitor, on lymphoid malignant cells, Leukemia. 21 (2007) 2344-2353. doi:10.1038/sj.leu.2404902.

[15] T. Hideshima, J.E. Bradner, J. Wong, D. Chauhan, P. Richardson, S.L. Schreiber, K.C. Anderson, Small-molecule inhibition of proteasome and aggresome function induces synergistic antitumor activity in multiple myeloma, Proc. Natl. Acad. Sci. U. S. A. 102 (2005) 8567-8572. doi:10.1073/pnas.0503221102.

[16] M.-T. Mackmull, M. Iskar, L. Parca, S. Singer, P. Bork, A. Ori, M. Beck, Histone Deacetylase Inhibitors (HDACi) Cause the Selective Depletion of Bromodomain Containing Proteins (BCPs), Mol. Cell. Proteomics. 14 (2015) 1350-1360. doi:10.1074/mcp.M114.042499.

[17] A. Martín-Bernabé, R. Cortés, S.G. Lehmann, M. Seve, M. Cascante, S. BourgoinVoillard, Quantitative proteomic approach to understand metabolic adaptation in nonsmall cell lung cancer, J. Proteome Res. 13 (2014) 4695-4704. doi:10.1021/pr500327v.

[18] S.G. Lehmann, S. Bourgoin-Voillard, M. Seve, W. Rachidi, Tubulin Beta-3 Chain as a New Candidate Protein Biomarker of Human Skin Aging: A Preliminary Study, Oxid. Med. Cell. Longev. 2017 (2017) 5140360. doi:10.1155/2017/5140360.

[19] F.P. Breitwieser, A. Müller, L. Dayon, T. Köcher, A. Hainard, P. Pichler, U. SchmidtErfurth, G. Superti-Furga, J.-C. Sanchez, K. Mechtler, K.L. Bennett, J. Colinge, General statistical modeling of data from protein relative expression isobaric tags, J. Proteome Res. 10 (2011) 2758-2766. doi:10.1021/pr1012784. 
[20] T. Hulsen, J. de Vlieg, W. Alkema, BioVenn - a web application for the comparison and visualization of biological lists using area-proportional Venn diagrams, BMC Genomics. 9 (2008) 488. doi:10.1186/1471-2164-9-488.

[21] J.A. Vizcaíno, E.W. Deutsch, R. Wang, A. Csordas, F. Reisinger, D. Ríos, J.A. Dianes, Z. Sun, T. Farrah, N. Bandeira, P.-A. Binz, I. Xenarios, M. Eisenacher, G. Mayer, L. Gatto, A. Campos, R.J. Chalkley, H.-J. Kraus, J.P. Albar, S. Martinez-Bartolomé, R. Apweiler, G.S. Omenn, L. Martens, A.R. Jones, H. Hermjakob, ProteomeXchange provides globally coordinated proteomics data submission and dissemination, Nat. Biotechnol. 32 (2014) 223-226. doi:10.1038/nbt.2839.

[22] H. Mi, A. Muruganujan, P.D. Thomas, PANTHER in 2013: modeling the evolution of gene function, and other gene attributes, in the context of phylogenetic trees, Nucleic Acids Res. 41 (2013) D377-386. doi:10.1093/nar/gks1118.

[23] M. Kutmon, M.P. van Iersel, A. Bohler, T. Kelder, N. Nunes, A.R. Pico, C.T. Evelo, PathVisio 3: an extendable pathway analysis toolbox, PLoS Comput. Biol. 11 (2015) e1004085. doi:10.1371/journal.pcbi.1004085.

[24] A.M. Curran, C. Fogarty Draper, M.-P. Scott-Boyer, A. Valsesia, H.M. Roche, M.F. Ryan, M.J. Gibney, M. Kutmon, C.T. Evelo, S.L. Coort, A. Astrup, W.H. Saris, L. Brennan, J. Kaput, Sexual Dimorphism, Age, and Fat Mass Are Key Phenotypic Drivers of Proteomic Signatures, J. Proteome Res. $16 \quad$ (2017) 4122-4133. doi:10.1021/acs.jproteome.7b00501.

[25] H.S. Kim, M.-S. Lee, STAT1 as a key modulator of cell death, Cell. Signal. 19 (2007) 454-465. doi:10.1016/j.cellsig.2006.09.003.

[26] N.C. Reich, STATs get their move on, JAK-STAT. 2 (2013) e27080. doi: $10.4161 / \mathrm{jkst} .27080$.

[27] W. Abbas, A. Kumar, G. Herbein, The eEF1A Proteins: At the Crossroads of Oncogenesis, Apoptosis, and Viral Infections, Front. Oncol. 5 (2015) 75. doi:10.3389/fonc.2015.00075.

[28] Y. Yang, S. Zhang, K. Howe, D.B. Wilson, F. Moser, D. Irwin, T.W. Thannhauser, A Comparison of nLC-ESI-MS/MS and nLC-MALDI-MS/MS for GeLC-Based Protein Identification and iTRAQ-Based Shotgun Quantitative Proteomics, J. Biomol. Tech. JBT. 18 (2007) 226-237.

[29] S.L. Shirran, C.H. Botting, A comparison of the accuracy of iTRAQ quantification by nLC-ESI MSMS and nLC-MALDI MSMS methods, J. Proteomics. 73 (2010) 13911403. doi:10.1016/j.jprot.2010.03.003.

[30] R. Moulder, S.D. Bhosale, D.R. Goodlett, R. Lahesmaa, Analysis of the plasma proteome using iTRAQ and TMT-based Isobaric labeling, Mass Spectrom. Rev. (n.d.) n/a-n/a. doi:10.1002/mas.21550.

[31] S. Gonfloni, V. Caputo, V. Iannizzotto, P63 in health and cancer, Int. J. Dev. Biol. 59 (2015) 87-93. doi:10.1387/ijdb.150045sg.

[32] F.-M. Boisvert, Y.W. Lam, D. Lamont, A.I. Lamond, A Quantitative Proteomics Analysis of Subcellular Proteome Localization and Changes Induced by DNA Damage, Mol. Cell. Proteomics MCP. 9 (2010) 457-470. doi:10.1074/mcp.M900429-MCP200.

[33] A. Gurtner, E. Falcone, F. Garibaldi, G. Piaggio, Dysregulation of microRNA biogenesis in cancer: the impact of mutant p53 on Drosha complex activity, J. Exp. Clin. Cancer Res. 35 (2016) 45. doi:10.1186/s13046-016-0319-x.

[34] S. Lin, R.I. Gregory, MicroRNA biogenesis pathways in cancer, Nat. Rev. Cancer. 15 (2015) 321-333. doi:10.1038/nrc3932.

[35] K. Mizuno, H. Mataki, N. Seki, T. Kumamoto, K. Kamikawaji, H. Inoue, MicroRNAs in non-small cell lung cancer and idiopathic pulmonary fibrosis, J. Hum. Genet. 62 (2017) 57-65. doi:10.1038/jhg.2016.98. 
[36] T.K. Sin, F. Wang, F. Meng, S.C.C. Wong, W.C.S. Cho, P.M. Siu, L.W.C. Chan, B.Y.M. Yung, Implications of MicroRNAs in the Treatment of Gefitinib-Resistant NonSmall Cell Lung Cancer, Int. J. Mol. Sci. 17 (2016) 237. doi:10.3390/ijms17020237.

[37] M. Serizawa, M. Kusuhara, V. Zangiacomi, K. Urakami, M. Watanabe, T. Takahashi, K. Yamaguchi, N. Yamamoto, Y. Koh, Identification of Metabolic Signatures Associated with Erlotinib Resistance of Non-small Cell Lung Cancer Cells, Anticancer Res. 34 (2014) 2779-2787.

[38] S.L. Blair, P. Heerdt, S. Sachar, A. Abolhoda, S. Hochwald, H. Cheng, M. Burt, Glutathione metabolism in patients with non-small cell lung cancers, Cancer Res. 57 (1997) 152-155.

[39] P. Yang, J.O. Ebbert, Z. Sun, R.M. Weinshilboum, Role of the glutathione metabolic pathway in lung cancer treatment and prognosis: A review, J. Clin. Oncol. 24 (2006) 1761-1769. doi:10.1200/JCO.2005.02.7110.

[40] A. Stephanou, D.S. Latchman, STAT-1: a novel regulator of apoptosis, Int. J. Exp. Pathol. 84 (2003) 239-244.

[41] K. Meissl, S. Macho-Maschler, M. Müller, B. Strobl, The good and the bad faces of STAT1 in solid tumours, Cytokine. 89 (2017) 12-20. doi:10.1016/j.cyto.2015.11.011.

[42] E.A. Stronach, A. Alfraidi, N. Rama, C. Datler, J.B. Studd, R. Agarwal, T.G. Guney, C. Gourley, B.T. Hennessy, G.B. Mills, A. Mai, R. Brown, R. Dina, H. Gabra, HDAC4regulated STAT1 activation mediates platinum resistance in ovarian cancer, Cancer Res. 71 (2011) 4412-4422. doi:10.1158/0008-5472.CAN-10-4111.

[43] C. Kaewpiboon, R. Srisuttee, W. Malilas, J. Moon, S. Oh, H.G. Jeong, R.N. Johnston, W. Assavalapsakul, Y.-H. Chung, Upregulation of Stat1-HDAC4 confers resistance to etoposide through enhanced multidrug resistance 1 expression in human A549 lung cancer cells, Mol. Med. Rep. 11 (2015) 2315-2321. doi:10.3892/mmr.2014.2949.

[44] G. Kulkarni, D.A. Turbin, A. Amiri, S. Jeganathan, M.A. Andrade-Navarro, T.D. Wu, D.G. Huntsman, J.M. Lee, Expression of protein elongation factor eEF1A2 predicts favorable outcome in breast cancer, Breast Cancer Res. Treat. 102 (2007) 31-41. doi:10.1007/s10549-006-9315-8.

[45] R. Li, H. Wang, B.N. Bekele, Z. Yin, N.P. Caraway, R.L. Katz, S.A. Stass, F. Jiang, Identification of putative oncogenes in lung adenocarcinoma by a comprehensive functional genomic approach, Oncogene. 25 (2006) 2628-2635. doi:10.1038/sj.onc. 1209289 .

[46] N. Anand, S. Murthy, G. Amann, M. Wernick, L.A. Porter, I.H. Cukier, C. Collins, J.W. Gray, J. Diebold, D.J. Demetrick, J.M. Lee, Protein elongation factor EEF1A2 is a putative oncogene in ovarian cancer, Nat. Genet. 31 (2002) 301-305. doi:10.1038/ng904.

[47] D.E. Pinke, S.E. Kalloger, T. Francetic, D.G. Huntsman, J.M. Lee, The prognostic significance of elongation factor eEF1A2 in ovarian cancer, Gynecol. Oncol. 108 (2008) 561-568. doi:10.1016/j.ygyno.2007.11.019.

[48] H. Duanmin, X. Chao, Z. Qi, eEF1A2 protein expression correlates with lymph node metastasis and decreased survival in pancreatic ductal adenocarcinoma, Hepatogastroenterology. 60 (2013) 870-875. doi:10.5754/hge12869.

[49] L.-B. Ruest, R. Marcotte, E. Wang, Peptide Elongation Factor eEF1A-2/S1 Expression in Cultured Differentiated Myotubes and Its Protective Effect against Caspase-3mediated Apoptosis, J. Biol. Chem. 277 (2002) 5418-5425. doi:10.1074/jbc.M110685200.

[50] R. Chang, E. Wang, Mouse translation elongation factor eEF1A-2 interacts with Prdx-I to protect cells against apoptotic death induced by oxidative stress, J. Cell. Biochem. 100 (2007) 267-278. doi:10.1002/jcb.20969. 
[51] A. Losada, M.J. Muñoz-Alonso, C. García, P.A. Sánchez-Murcia, J.F. Martínez-Leal, J.M. Domínguez, M.P. Lillo, F. Gago, C.M. Galmarini, Translation Elongation Factor eEF1A2 is a Novel Anticancer Target for the Marine Natural Product Plitidepsin, Sci. Rep. 6 (2016) srep35100. doi:10.1038/srep35100.

[52] A. Amiri, F. Noei, S. Jeganathan, G. Kulkarni, D.E. Pinke, J.M. Lee, eEF1A2 activates Akt and stimulates Akt-dependent actin remodeling, invasion and migration, Oncogene. 26 (2007) 3027-3040. doi:10.1038/sj.onc.1210101.

[53] Z. Li, C.-F. Qi, D.-M. Shin, A. Zingone, H.J. Newbery, A.L. Kovalchuk, C.M. Abbott, H.C. Morse, Eefla2 promotes cell growth, inhibits apoptosis and activates JAK/STAT and AKT signaling in mouse plasmacytomas, PloS One. 5 (2010) e10755. doi:10.1371/journal.pone.0010755. 
Figures and Tables Legends

Table 1. List of proteins significantly dysregulated in gefitinib, TSA and NAM versus gefitinib treated cells (iTRAQ ratio 121/117).

Table 2. List of top enriched pathways provided after over-representation analysis with PathVisio

Table 3. List of subnetworks provided after network analysis with PathwayStudio

Figure 1. The number of identified, quantified and dysregulated proteins in the nucleus and in the cytoplasm (cells were treated with $0.5 \mu \mathrm{mol} / \mathrm{L}$ gefitinib, $200 \mathrm{ng} / \mathrm{mL}$ trichostatin A and $5 \mathrm{mmol} / \mathrm{L}$ nicotinamide combination versus gefitinib only). Venn diagrams showing the identified/quantified proteins according to their localization in the nucleus and/or in the cytoplasm.

Figure 2. Functional distribution of the 86 proteins identified as dysregulated in the nucleus and in the cytoplasm when treated with gefitinib, trichostatin $A$ and nicotinamide combination versus gefitinib only according to biological processes (A), and molecular functions $(B)$ categories.

Figure 3. Upstream neighbors of apoptosis for the 57 proteins reported as directly related to this process by the subnetwork analysis of the 86 dysregulated proteins in the nucleus and in the cytoplasm when treated with gefitinib, trichostatin $A$ and nicotinamide combination versus gefitinib only.

Figure 4. (A) Representative Western blot analysis on nuclear and cytoplasmic extracts of $\mathrm{H358}$ cells treated with $200 \mathrm{ng} / \mathrm{mL}$ trichostatin $A$ and $5 \mathrm{mmol} / \mathrm{L}$ nicotinamide (TSA/NAM) and/or $0.5 \mu \mathrm{mol} / \mathrm{L}$ gefitinib as indicated for 96h for STAT1, P63 and eEF1A2. (B) Quantification of cytoplasmic eEF1A2, STAT1-alpha, STAT1-beta, and nuclear p63-alpha protein levels was performed as described in the method sections $(\mathbf{n}=3)$. 
Figure 5. Effects of eEF1A2 and STAT1 silencing on AKT activation, cell viability and apoptosis. A: Representative immunoblots of eEF1A2, STAT1 and phosphorylated AKT (pAKT) in cells treated as indicated. B: Cell viability in cells treated as indicated $(n=3)$. C: Apoptosis was measured by flow cytometry analysis of active caspase-3 in cells treated as indicated $(n=3)$. 
Table 1: List of human proteins significantly dysregulated in gefitinib, TSA and NAM versus gefitinib treated cells (iTRAQ ratio 121/117). Statistically significant iTRAQ ratios ( $p$-value ratio and $p$-value sample $\leq 0.05$ ) for the 86 proteins that are dysregulated in the nuclear and the cytoplasmic extracts.

\begin{tabular}{|c|c|c|c|c|c|}
\hline $\begin{array}{l}\text { GENE } \\
\text { SYMIBOL }\end{array}$ & $\begin{array}{l}\text { ACCESSION } \\
\text { NUMIBER }\end{array}$ & $\begin{array}{c}\text { PROTEIN } \\
\text { NAMIES }\end{array}$ & $\begin{array}{l}\text { ITRAQ } \\
\text { RATIO }\end{array}$ & $\begin{array}{c}\text { P-VALUE } \\
\text { RATIO }\end{array}$ & $\begin{array}{l}\text { P-VALUE } \\
\text { SAMIPLE }\end{array}$ \\
\hline \multicolumn{6}{|c|}{ CYTOPLASMIC EXTRACT } \\
\hline NCKAP1 & Q9Y2A7 & Nck-associated protein 1 (NAP 1) & 0.24 & $1.13 \times 10^{-02}$ & $1.49 \times 10^{-13}$ \\
\hline $\mathrm{TF}$ & P02787 & Serotransferrin (Transferrin) & 0.28 & $1.09 \times 10^{-02}$ & $4.77 \times 10^{-11}$ \\
\hline ITPA & Q9BY32 & Inosine triphosphate pyrophosphatase & 0.34 & $2.66 \times 10^{-02}$ & $1.01 \times 10^{-08}$ \\
\hline DPYSL2 & Q16555 & Dihydropyrimidinase-related protein 2 & 0.35 & $1.46 \times 10^{-02}$ & $2.66 \times 10^{-08}$ \\
\hline SNX6 & Q9UNH7 & Sorting nexin-6(TRAF4-associated factor 2 ) & 0.38 & $8.36 \times 10^{-03}$ & $3.73 \times 10^{-07}$ \\
\hline LPP & Q93052 & Lipoma-preferred partner & 0.38 & $3.35 \times 10^{-02}$ & $3.76 \times 10^{-07}$ \\
\hline RSG1 & Q9BU20 & REM2-and Rab-like small GTPase 1 & 0.38 & $3.48 \times 10^{-05}$ & $4.77 \times 10^{-07}$ \\
\hline MYO18A & Q92614 & Unconventional myosin-XVIIIa & 0.41 & $2.84 \times 10^{-02}$ & $2.23 \times 10^{-06}$ \\
\hline S100P & P25815 & Protein S100-P & 0.43 & $5.51 \times 10^{-03}$ & $7.34 \times 10^{-06}$ \\
\hline RPL13A & P40429 & $60 \mathrm{~S}$ ribosomal protein $\mathrm{L} 13 \mathrm{a}$ & 0.43 & $4.62 \times 10^{-02}$ & $7.54 \times 10^{-06}$ \\
\hline PAICS & $\mathrm{P} 22234$ & Multifunctional protein $\mathrm{ADE} 2$ & 0.44 & $2.03 \times 10^{-02}$ & $1.11 \times 10^{-05}$ \\
\hline DLGAP5 & Q15398 & Disks large-associated protein 5 (DAP-5) & 0.45 & $1.52 \times 10^{-02}$ & $2.40 \times 10^{-05}$ \\
\hline RPS15 & P62841 & 40S ribosomal protein $\mathrm{S} 15$ (RIG protein) & 0.47 & $3.76 \times 10^{-02}$ & $5.34 \times 10^{-05}$ \\
\hline AARS & P49588 & Alanine-tRNA ligase, cytoplasmic & 0.48 & $3.22 \times 10^{-05}$ & $6.79 \times 10^{-05}$ \\
\hline PRMT5 & O14744 & Protein arginine N-methyltransferase 5 & 0.50 & $4.89 \times 10^{-02}$ & $1.58 \times 10^{-04}$ \\
\hline BLVRB & P30043 & Flavin reductase(NADPH) & 0.53 & $1.38 \times 10^{-04}$ & $5.04 \times 10^{-04}$ \\
\hline IPO5 & O00410 & Importin-5 (Imp5) & 0.55 & $3.98 \times 10^{-05}$ & $9.55 \times 10^{-04}$ \\
\hline UBE2V2 & Q15819 & Ubiquitin-conjugating enzyme $\mathrm{E} 2$ variant 2 & 0.55 & $4.52 \times 10^{-02}$ & $1.17 \times 10^{-03}$ \\
\hline MAP4 & P27816 & Microtubule-associated protein 4 & 0.56 & $1.61 \times 10^{-06}$ & $1.56 \times 10^{-03}$ \\
\hline CAB39 & Q9Y376 & Calcium-binding protein 39(MO25alpha) & 0.56 & $6.47 \times 10^{-05}$ & $1.65 \times 10^{-03}$ \\
\hline EEF1A2 & Q05639 & $\begin{array}{l}\text { Elongation factor 1-alpha } 2 \text { (Eukaryotic elongation factor } \\
1 \text { A-2) (eEF1A-2) }\end{array}$ & 0.57 & $4.09 \times 10^{-02}$ & $1.93 \times 10^{-03}$ \\
\hline GART & P22102 & Trifunctional purine biosynthetic protein adenosine-3 & 0.57 & $9.54 \times 10^{-03}$ & $2.12 \times 10^{-03}$ \\
\hline TARS & P26639 & Threonine-tRNA ligase, cytoplasmic & 0.58 & $8.90 \times 10^{-05}$ & $2.61 \times 10^{-03}$ \\
\hline UBE2N & P61088 & Ubiquitin-conjugating enzyme E2 N & 0.59 & $2.97 \times 10^{-02}$ & $3.80 \times 10^{-03}$ \\
\hline CCT7 & Q99832 & T-complex protein 1 subunit eta & 0.61 & $3.99 \times 10^{-04}$ & $5.31 \times 10^{-03}$ \\
\hline UGDH & O60701 & UDP-glucose 6-dehydrogenase & 0.63 & $2.31 \times 10^{-02}$ & $9.19 \times 10^{-03}$ \\
\hline STAT1 & P42224 & $\begin{array}{l}\text { Signal transducer and activator of transcription 1- } \\
\text { alpha/beta(STAT1) }\end{array}$ & 0.65 & $7.42 \times 10^{-03}$ & $1.42 \times 10^{-02}$ \\
\hline ECI1 & P42126 & Enoyl-CoA delta isomerase 1, mitochondrial & 0.66 & $1.97 \times 10^{-03}$ & $1.56 \times 10^{-02}$ \\
\hline RPS3 & $\mathrm{P} 23396$ & 40 S ribosomal protein $\mathrm{S} 3$ & 0.68 & $7.78 \times 10^{-03}$ & $2.25 \times 10^{-02}$ \\
\hline C9orf64 & Q5T6V5 & UPF0553 protein C9orf64 & 0.68 & $1.07 \times 10^{-02}$ & $2.44 \times 10^{-02}$ \\
\hline WARS & P23381 & Tryptophan-tRNA ligase, cytoplasmic & 0.68 & $1.05 \times 10^{-02}$ & $2.48 \times 10^{-02}$ \\
\hline EIF5A & P63241 & Eukaryotic translation initiation factor 5A-1 (eIF-5A-1) & 0.68 & $2.35 \times 10^{-03}$ & $2.49 \times 10^{-02}$ \\
\hline EIF1AX & P47813 & $\begin{array}{l}\text { Eukaryotic translation initiation factor } 1 \mathrm{~A}, \mathrm{X}- \\
\text { chromosomal (eIF-1AX isoform) }\end{array}$ & 0.68 & $1.13 \times 10^{-02}$ & $2.53 \times 10^{-02}$ \\
\hline S100A6 & P06703 & Protein S100-A6(Calcyclin) & 0.69 & $1.78 \times 10^{-02}$ & $2.96 \times 10^{-02}$ \\
\hline IQGAP1 & P46940 & Ras GTPase-activating-like protein IQGAP1 (p195) & 0.69 & $3.47 \times 10^{-02}$ & $2.98 \times 10^{-02}$ \\
\hline SERBP1 & Q8NC51 & Plasminogen activator inhibitor 1 RNA-binding protein & 0.70 & $1.74 \times 10^{-02}$ & $3.31 \times 10^{-02}$ \\
\hline PPA2 & Q9H2U2 & Inorganic pyrophosphatase 2 , mitochondrial & 1.44 & $1.14 \times 10^{-02}$ & $3.00 \times 10^{-02}$ \\
\hline TACSTD2 & P09758 & Tumor-associated calcium signal transducer 2 & 1.53 & $1.50 \times 10^{-02}$ & $1.44 \times 10^{-02}$ \\
\hline STOML2 & Q9UJZ1 & Stomatin-like protein 2 , mitochondrial & 1.60 & $2.62 \times 10^{-02}$ & $7.77 \times 10^{-03}$ \\
\hline GAA & P10253 & Lysosomal alpha-glucosidase & 1.63 & $2.41 \times 10^{-03}$ & $6.16 \times 10^{-03}$ \\
\hline HNRNPK & P61978 & Heterogeneous nuclear ribonucleoprotein $\mathrm{K}$ (hnRNPK) & 1.65 & $3.67 \times 10^{-02}$ & $4.98 \times 10^{-03}$ \\
\hline DHRS2 & Q13268 & $\begin{array}{l}\text { Dehydrogenase/reductase SDR family member } 2 \text {, } \\
\text { mitochondrial }\end{array}$ & 1.73 & $3.93 \times 10^{-02}$ & $2.38 \times 10^{-03}$ \\
\hline TMED10 & P49755 & Transmembrane emp24 domain-containing protein 10 & 1.76 & $2.90 \times 10^{-02}$ & $1.86 \times 10^{-03}$ \\
\hline IDH1 & $\mathrm{O} 75874$ & Isocitrate dehydrogenase [NADP] cytoplasmic (IDH) & 1.78 & $2.23 \times 10^{-03}$ & $1.61 \times 10^{-03}$ \\
\hline SCARB2 & Q14108 & $\begin{array}{l}\text { Lysosome membrane protein } 2 \text { ( } 85 \mathrm{kDa} \text { lysosomal } \\
\text { membrane sialoglycoprotein) }\end{array}$ & 1.87 & $2.86 \times 10^{-12}$ & $6.92 \times 10^{-04}$ \\
\hline
\end{tabular}




\begin{tabular}{|c|c|c|c|c|c|}
\hline ACOT9 & Q9Y305 & Acyl-coenzyme A thioesterase 9, mitochondrial & 1.95 & $4.33 \times 10^{-12}$ & $3.18 \times 10^{-04}$ \\
\hline F11R & Q9Y624 & Junctional adhesion molecule A & 2.00 & $4.30 \times 10^{-12}$ & $1.96 \times 10^{-04}$ \\
\hline PREP & P48147 & Prolyl endopeptidase & 2.00 & $3.06 \times 10^{-02}$ & $1.93 \times 10^{-04}$ \\
\hline GCN1 & Q92616 & Translational activator GCN1 & 2.02 & $3.53 \times 10^{-12}$ & $1.55 \times 10^{-04}$ \\
\hline PPP1R7 & Q15435 & Protein phosphatase 1 regulatory subunit 7 & 2.17 & $3.02 \times 10^{-12}$ & $3.47 \times 10^{-05}$ \\
\hline GNL1 & P36915 & $\begin{array}{l}\text { Guanine nucleotide-binding protein-like } 1 \text { (GTP-binding } \\
\text { protein HSR1) }\end{array}$ & 2.36 & $4.99 \times 10^{-12}$ & $5.50 \times 10^{-06}$ \\
\hline NMRAL1 & Q9HBL8 & NmrA-like family domain-containing protein 1 & 2.44 & $4.43 \times 10^{-12}$ & $2.38 \times 10^{-06}$ \\
\hline TECR & Q9NZ01 & Very-long-chain enoyl-CoA reductase & 2.51 & $3.87 \times 10^{-12}$ & $1.14 \times 10^{-06}$ \\
\hline PROSC & O94903 & $\begin{array}{l}\text { Proline synthase co-transcribed bacterial homolog } \\
\text { protein }\end{array}$ & 2.61 & $4.25 \times 10^{-12}$ & $4.20 \times 10^{-07}$ \\
\hline RABL6 & Q3YEC7 & Rab-like protein 6(GTP-binding protein Parf) & 2.62 & $3.20 \times 10^{-12}$ & $3.97 \times 10^{-07}$ \\
\hline TIMM50 & Q3ZCQ8 & $\begin{array}{l}\text { Mitochondrial import inner membrane translocase } \\
\text { subunit TIM50 }\end{array}$ & 2.64 & $1.56 \times 10^{-12}$ & $3.32 \times 10^{-07}$ \\
\hline DPM1 & O60762 & Dolichol-phosphate mannosyltransferase subunit 1 & 2.67 & $4.46 \times 10^{-12}$ & $2.32 \times 10^{-07}$ \\
\hline CARS & P49589 & Cysteine-tRNA ligase, cytoplasmic & 2.68 & $2.56 \times 10^{-12}$ & $2.21 \times 10^{-07}$ \\
\hline PDP1 & Q9P0J1 & $\begin{array}{l}\text { [Pyruvate dehydrogenase [acetyl-transferring]]- } \\
\text { phosphatase 1, mitochondrial(PDP 1) }\end{array}$ & 2.68 & $3.91 \times 10^{-12}$ & $2.09 \times 10^{-07}$ \\
\hline TBCA & O75347 & Tubulin-specific chaperone A & 2.77 & $2.32 \times 10^{-02}$ & $8.43 \times 10^{-08}$ \\
\hline HSPA2 & P54652 & Heat shock-related $70 \mathrm{kDapprotein} 2$ & 2.98 & $2.66 \times 10^{-12}$ & $1.08 \times 10^{-08}$ \\
\hline UBXN7 & O94888 & UBX domain-containing protein 7 & 3.02 & $2.63 \times 10^{-02}$ & $7.04 \times 10^{-09}$ \\
\hline EIF3M & Q7L2H7 & $\begin{array}{l}\text { Eukaryotic translation initiation factor } 3 \text { subunit } \mathrm{M} \\
(\mathrm{eIF} 3 \mathrm{~m})\end{array}$ & 3.17 & $3.84 \times 10^{-12}$ & $1.70 \times 10^{-99}$ \\
\hline CRIP2 & P52943 & Cysteine-rich protein 2(CRP-2) (Protein ESP1) & 3.21 & $4.93 \times 10^{-12}$ & $1.13 \times 10^{-99}$ \\
\hline VAPA & Q9P0L0 & $\begin{array}{l}\text { Vesicle-associated membrane protein-associated protein } \\
\text { A }\end{array}$ & 3.21 & $1.84 \times 10^{-12}$ & $1.06 \times 10^{-09}$ \\
\hline EXOC4 & Q96A65 & Exocyst complex component 4 & 3.31 & $2.90 \times 10^{-02}$ & $4.15 \times 10^{-10}$ \\
\hline AP2B1 & P63010 & AP-2 complex subunit beta (AP105B) & 3.70 & $1.68 \times 10^{-02}$ & $9.43 \times 10^{-12}$ \\
\hline UCHL5 & Q9Y5K5 & $\begin{array}{l}\text { Ubiquitin carboxyl-terminal hydrolase isozyme L5 } \\
\text { (UCH-L5) }\end{array}$ & 3.92 & $2.36 \times 10^{-12}$ & $1.24 \times 10^{-12}$ \\
\hline PRKRA & O75569 & $\begin{array}{l}\text { Interferon-inducible double-stranded RNA-dependent } \\
\text { protein kinase activator A }\end{array}$ & 4.28 & $1.32 \times 10^{-12}$ & $4.46 \times 10^{-14}$ \\
\hline KRT6B & P04259 & Keratin, type II cytoskeletal 6B & 5.31 & $1.46 \times 10^{-12}$ & $5.41 \times 10^{-18}$ \\
\hline FLII & Q13045 & Protein flightless-1 homolog & 7.05 & $4.22 \times 10^{-13}$ & $6.14 \times 10^{-24}$ \\
\hline \multicolumn{6}{|c|}{ NUCLEAR EXTRACT } \\
\hline CKAP4 & Q07065 & Cytoskeleton-associated protein 4 (P63; CKAP4) & 0.24 & $1.90 \times 10^{-02}$ & $1.22 \times 10^{-13}$ \\
\hline ENO1 & P06733 & Alpha-enolase & 0.50 & $1.07 \times 10^{-02}$ & $2.13 \times 10^{-04}$ \\
\hline ACTN1 & 2814 & & 0.52 & $3.64 \times 10^{-04}$ & $3.91 \times 10^{-04}$ \\
\hline SLC3A2 & P08195 & $4 \mathrm{~F} 2$ cell-surface antigen heavy chain & 0.53 & $9.57 \times 10^{-06}$ & $6.19 \times 10^{-04}$ \\
\hline API5 & Q9B775 & Apoptosis inhibitor 5 & 0.62 & $2.51 \times 10^{-13}$ & $7.34 \times 10^{-13}$ \\
\hline HSPE1 & P61604 & $10 \mathrm{kDa}$ heat shock protein, mitochondrial (Hsp10) & 0.71 & $1.15 \times 10^{-02}$ & $4.18 \times 10^{-12}$ \\
\hline SF3B3 & Q15393 & Splicing factor $3 \mathrm{~B}$ subunit 3 & 1.43 & $4.69 \times 10^{-02}$ & $3.18 \times 10^{-12}$ \\
\hline RAN & P62826 & GTP-binding nuclear protein Ran & 1.45 & $5.10 \times 10^{-03}$ & $2.89 \times 10^{-12}$ \\
\hline ERH & P84090 & Enhancer of rudimentary homolog & 1.46 & $1.91 \times 10^{-02}$ & $2.58 \times 10^{-12}$ \\
\hline RPN2 & $\mathrm{P} 04844$ & $\begin{array}{l}\text { Dolichyl-diphosphooligosaccharide-protein } \\
\text { glycosyltransferase subunit } 2\end{array}$ & 1.52 & $7.22 \times 10^{-13}$ & $1.51 \times 10^{-2}$ \\
\hline PRMT1 & Q99873 & Protein arginine N-methyltransferase 1 & 1.56 & $1.01 \times 10^{-12}$ & $1.07 \times 10^{-12}$ \\
\hline MATR3 & P43243 & Matrin-3 & 1.59 & $1.45 \times 10^{-12}$ & $8.24 \times 10^{-03}$ \\
\hline ATAD3A & Q9NVI7 & ATPase family AAA domain-containing protein $3 \mathrm{~A}$ & 1.71 & $1.14 \times 10^{-02}$ & $2.99 \times 10^{-13}$ \\
\hline HIST1H4I & P62805 & Histone $\mathrm{H} 4$ & 1.91 & $6.64 \times 10^{-03}$ & $4.45 \times 10^{-04}$ \\
\hline PAQR9 & Q6ZVX9 & Progestin and adipoQ receptor family member 9 & 2.68 & $4.22 \times 10^{-02}$ & $2.06 \times 10^{-07}$ \\
\hline
\end{tabular}


Table 2. List of top enriched pathways provided after over-representation analysis with PathVisio.

\begin{tabular}{|c|c|c|c|c|c|c|}
\hline \multicolumn{7}{|l|}{ PATHWAY ANALYSIS } \\
\hline Pathway Name & $\begin{array}{c}\text { Positive } \\
\text { (r) }\end{array}$ & $\begin{array}{l}\text { Measured } \\
\text { (n) }\end{array}$ & Total & $\%$ & Z Score & $\begin{array}{c}\text { p-value } \\
\text { (permuted) }\end{array}$ \\
\hline Histone Modifications* & 11 & 12 & 69 & 91.67 & 16.68 & $<0.001$ \\
\hline miRNA Biogenesis* & 1 & 1 & 8 & 100.00 & 5.23 & $<0.001$ \\
\hline Glutathione Metabolism* & 1 & 4 & 57 & 25.00 & 2.33 & 0.024 \\
\hline mRNA Processing & 4 & 47 & 130 & 8.51 & 1.91 & 0.048 \\
\hline
\end{tabular}

Positive ( $r$ ) is the number of genes in the pathway significantly dysregulated

Measured $(n)$ is the number of genes in the pathway measured in the experiment

Total is the total number of elements in the pathway

$\%$ is the percentage of genes dysregulated regarding to all genes measured in the pathway

Z-Score is the score calculated for over-representation analysis. Pathways with a high Z-Score have more significantly up- or down-regulated genes than expected.

The enrichment is significant for a p-value $<0.005$

*Only pathways with a Z-Score of $>1.96$ and a p-value of $<0.05$ were considered significantly affected [24] 
Table 3. List of sub-networks provided after network analysis with PathwayStudio.

\begin{tabular}{|c|c|c|c|}
\hline SUB-NETWORK ANALYSIS & & & \\
\hline Subnetwork Name & $\begin{array}{c}\text { Total } \\
\text { Number of } \\
\text { Neighbors }\end{array}$ & $\begin{array}{l}\text { Number of } \\
\text { measured } \\
\text { neighbors }\end{array}$ & p-value \\
\hline Upstream neighbors of nuclear receptor & 429 & 6 & 0.001 \\
\hline Upstream neighbors of apoptosis & 7490 & 57 & 0.003 \\
\hline Upstream neighbors of non-selective vesicle budding & 348 & 6 & 0.003 \\
\hline Upstream neighbors of cell migration & 4138 & 33 & 0.003 \\
\hline Upstream neighbors of microtubule & 1145 & 15 & 0.004 \\
\hline Upstream neighbors of spermatogenesis & 1140 & 5 & 0.004 \\
\hline Upstream neighbors of morphogenesis & 1918 & 8 & 0.004 \\
\hline
\end{tabular}




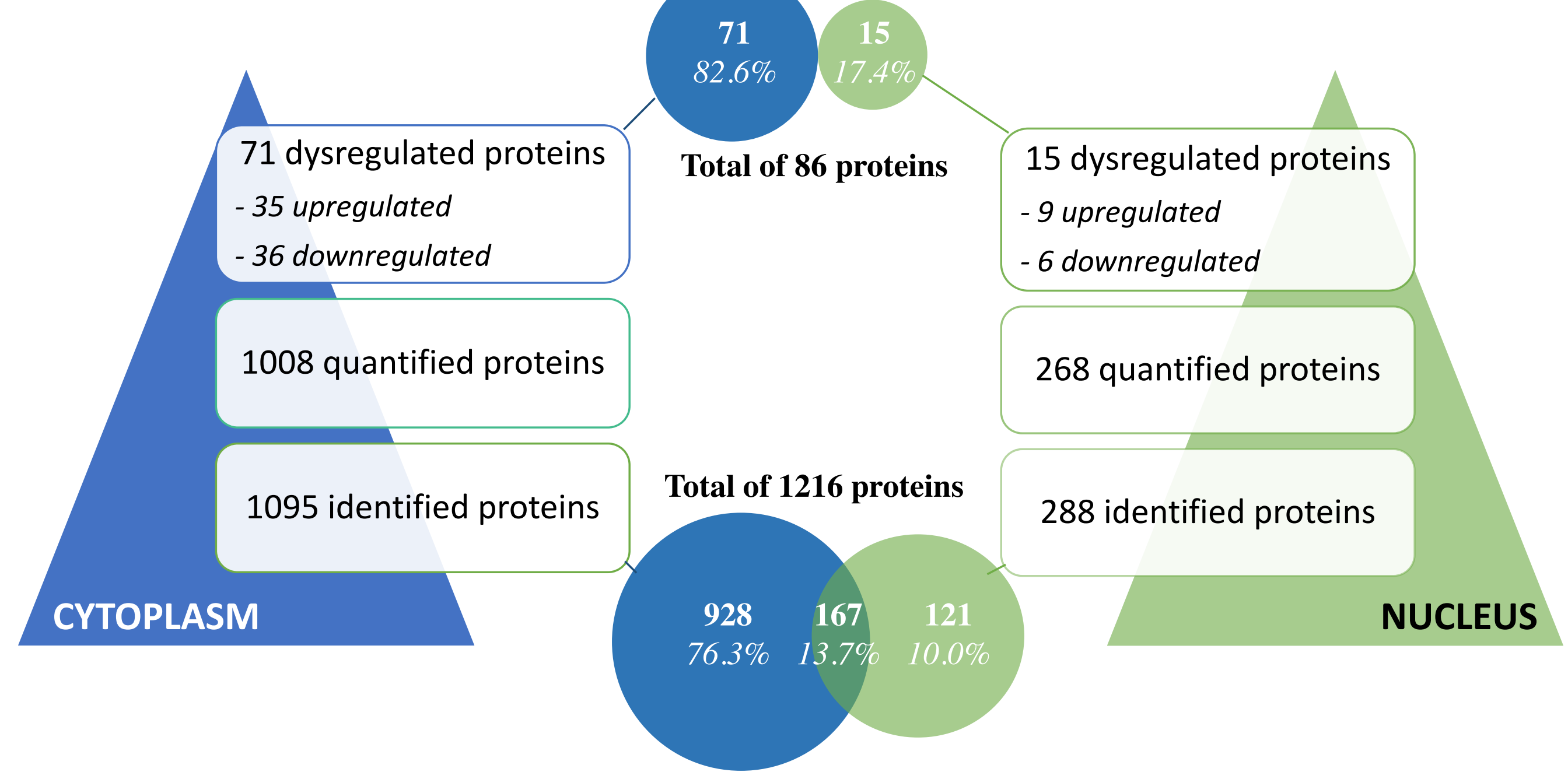

Figure 1. The number of identified, quantified and dysregulated proteins in the nucleus and in the cytoplasm (cells were treated with $0.5 \mu \mathrm{mol} / \mathrm{L}$ gefitinib, $200 \mathrm{ng} / \mathrm{mL}$ trichostatin A and $5 \mathrm{mmol} / \mathrm{L}$ nicotinamide combination versus gefitinib only). Venn diagrams showing the identified/quantified proteins according to their localization in the nucleus and/or in the cytoplasm. 


\section{A}

\section{B}

Reproduction (1.1\%)

Biological adhesion (0.5\%)

Metabolic process (primary metabolic process, nitrogen compound metabolic process, biosynthetic process, ...)

Development process (cell death including apoptosis, cell

differentiation, ...)

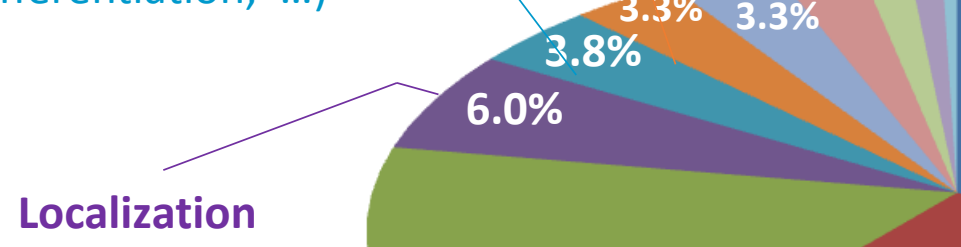

Localization

Cellular organization biogenesis

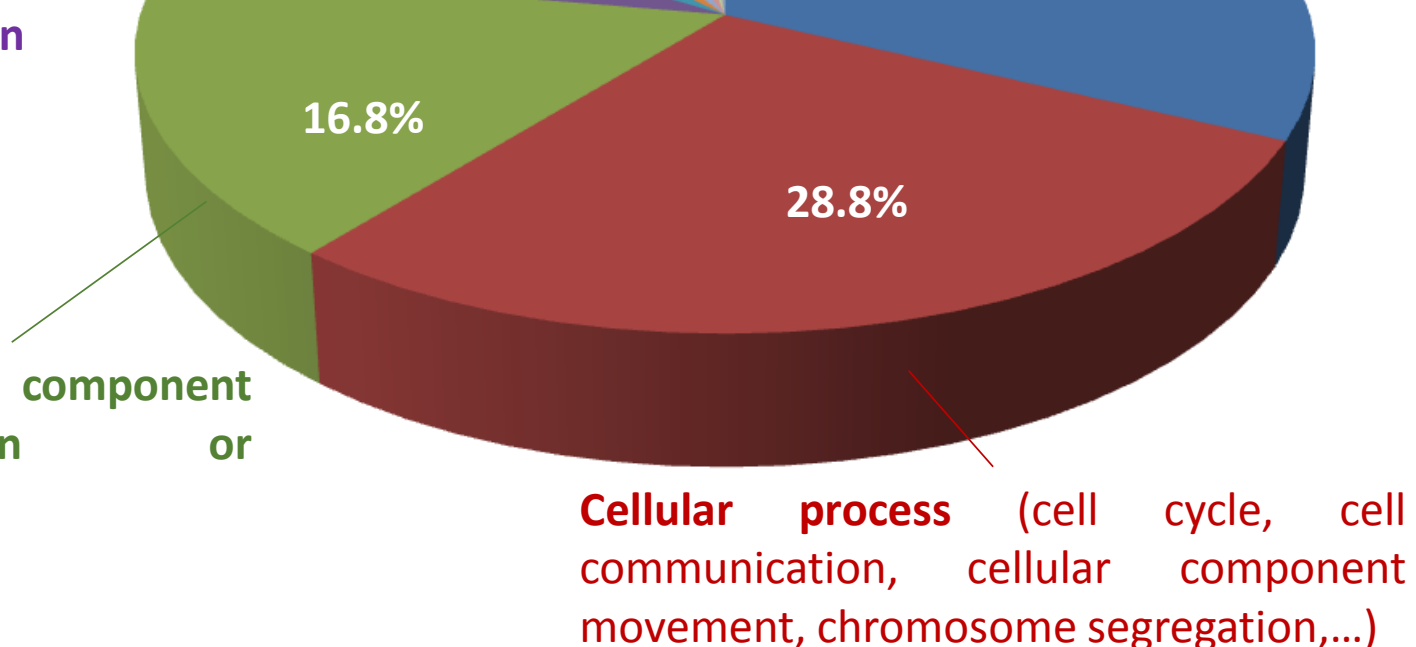

Translation regular activity (2.1\%)

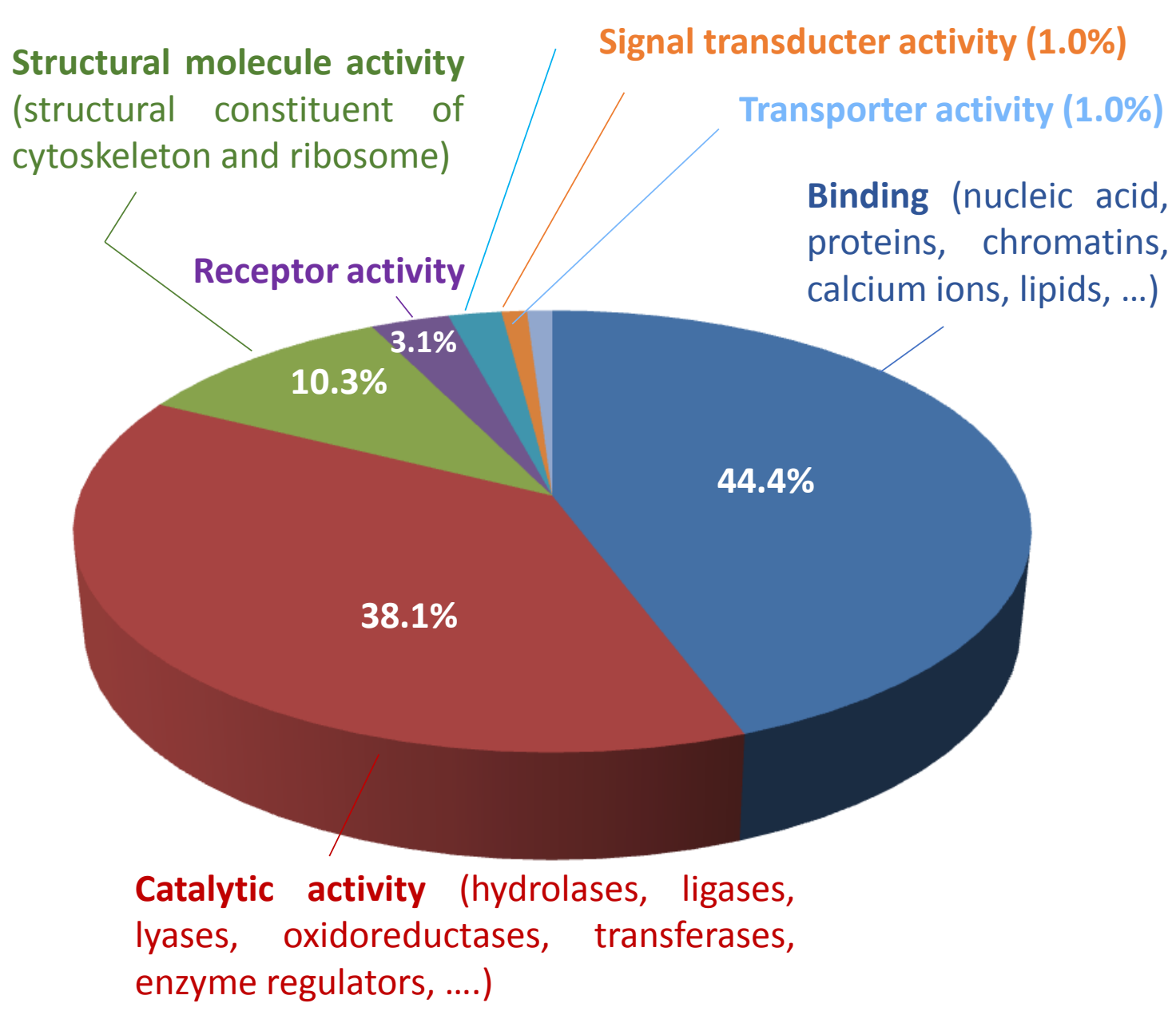

Figure 2. Functional distribution of the 86 proteins identified as dysregulated in the nucleus and in the cytoplasm when treated with gefitinib, trichostatin $A$ and nicotinamide combination versus gefitinib only according to biological processes (A), and molecular functions (B) categories. Assignment were made with PANTHER tool. The numbers in brackets correspond to the percentage of identified proteins classified in the category. If a protein is classified into 2 ontology terms that are not parent or child to each other, it counts in the 2 classes. 


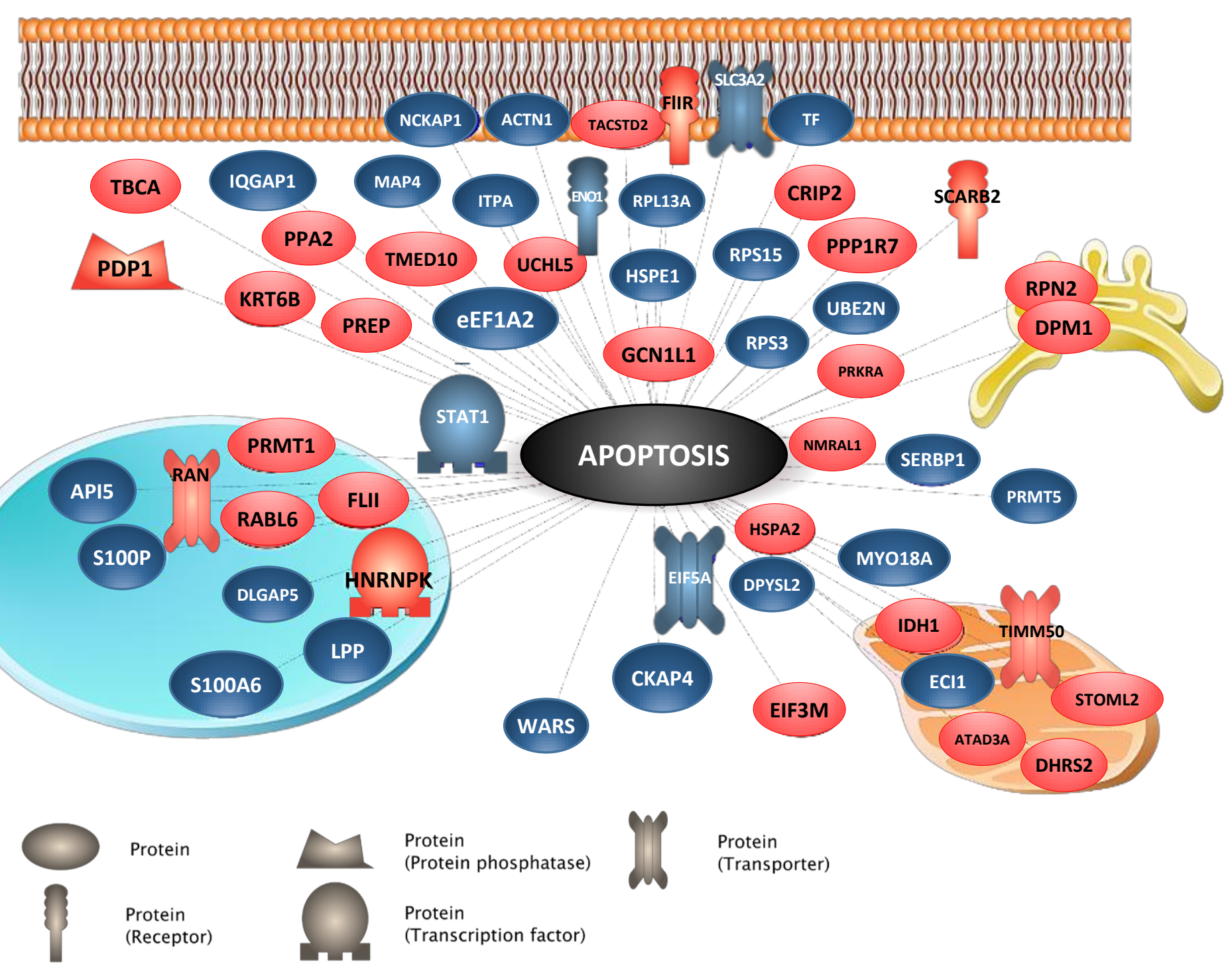

Figure 3. Upstream neighbors of apoptosis for the 57 proteins reported as directly related to this process by the subnetwork analysis of the $\mathbf{8 6}$ dysregulated proteins in the nucleus and in the cytoplasm when treated with gefitinib, trichostatin $A$ and nicotinamide combination versus gefitinib only. Proteins in red are upregulated (29) and those in blue are downregulated (28). The function of the protein is also represented as seen in the legend, and the link between the proteins and apoptosis is representing the regulation. 
A

\begin{tabular}{|c|c|c|c|c|c|c|c|}
\hline \multicolumn{3}{|c|}{ cytoplasmic } & \multicolumn{4}{|c|}{ nuclear } & \multirow{3}{*}{$\begin{array}{l}\text { TSA/NAM } \\
\text { gefitinib }\end{array}$} \\
\hline$-\quad-$ & + & + & - & - & + & + & \\
\hline+ & - & + & - & + & - & + & \\
\hline & & & & & & - & - Lamin B1 \\
\hline
\end{tabular}
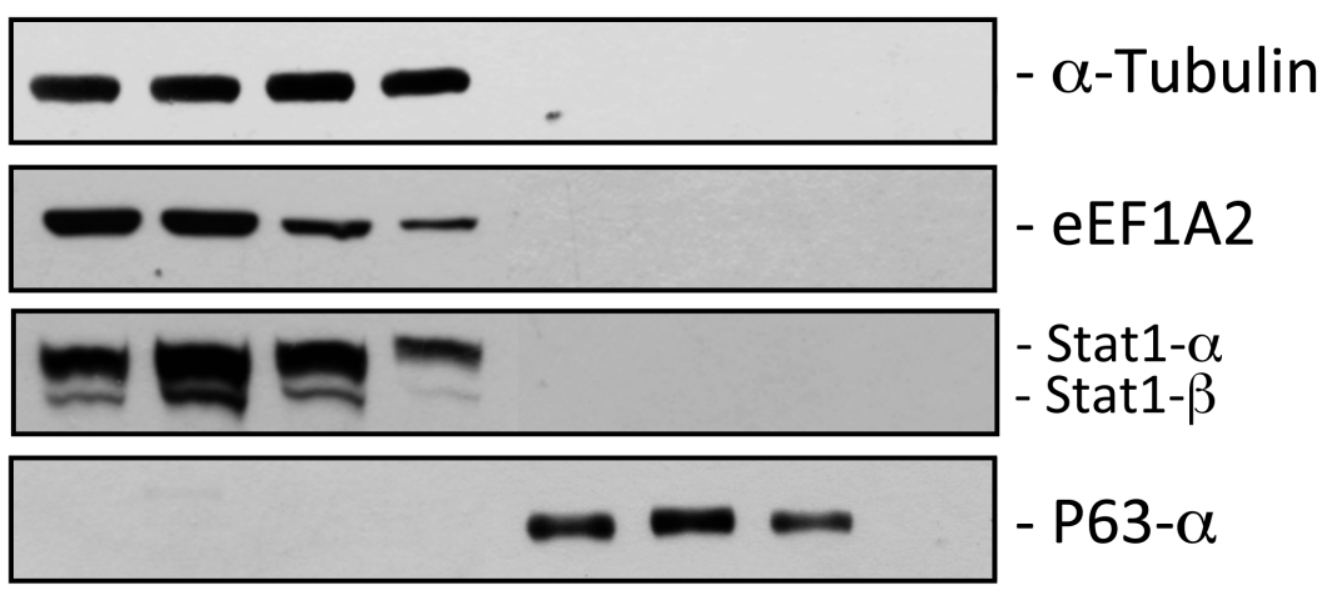
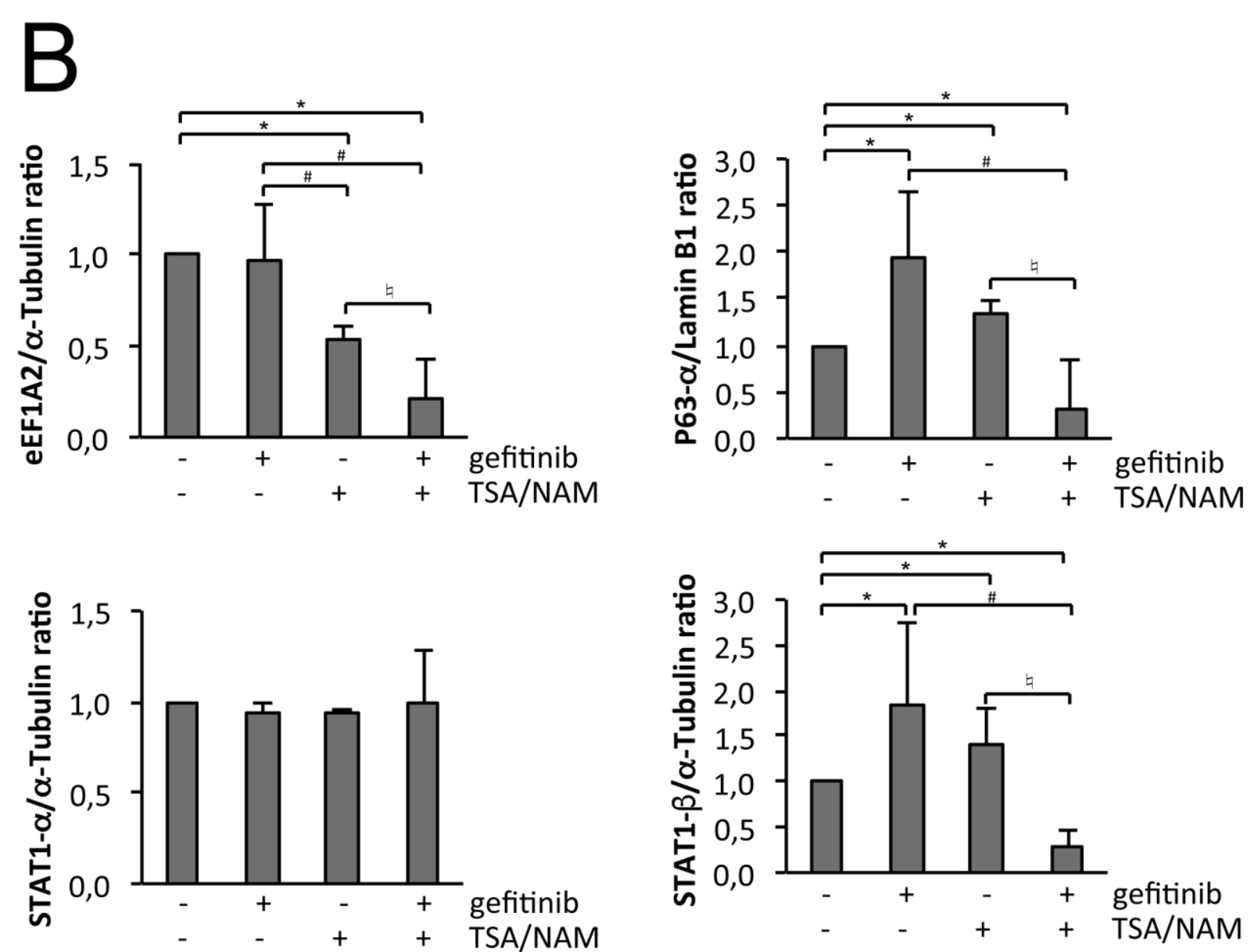

Figure 4. (A) Representative Western blot analysis on nuclear and cytoplasmic extracts of $\mathrm{H358}$ cells treated with 200 $\mathrm{ng} / \mathrm{mL}$ trichostatin A and $5 \mathrm{mmol} / \mathrm{L}$ nicotinamide (TSA/NAM) and/or $0.5 \mu \mathrm{mol} / \mathrm{L}$ gefitinib as indicated for $96 \mathrm{~h}$ for STAT1, P63 and eEF1A2. Lamin B1 and a-tubulin were used as nuclear and cytoplasmic loading control, respectively. (B) Quantification of cytoplasmic eEF1A2, STAT1-alpha, STAT1-beta, and nuclear p63-alpha protein levels was performed as described in the method sections $(\mathbf{n}=\mathbf{3}) .{ }^{*} \mathrm{p}<0.05$ for comparison between treated and control; ${ }^{*} \mathrm{p}<0.05$ for comparison between treated and gefitinib; ${ }^{4} \mathrm{p}<0.05$ for comparison between treated and TSA/NAM. 

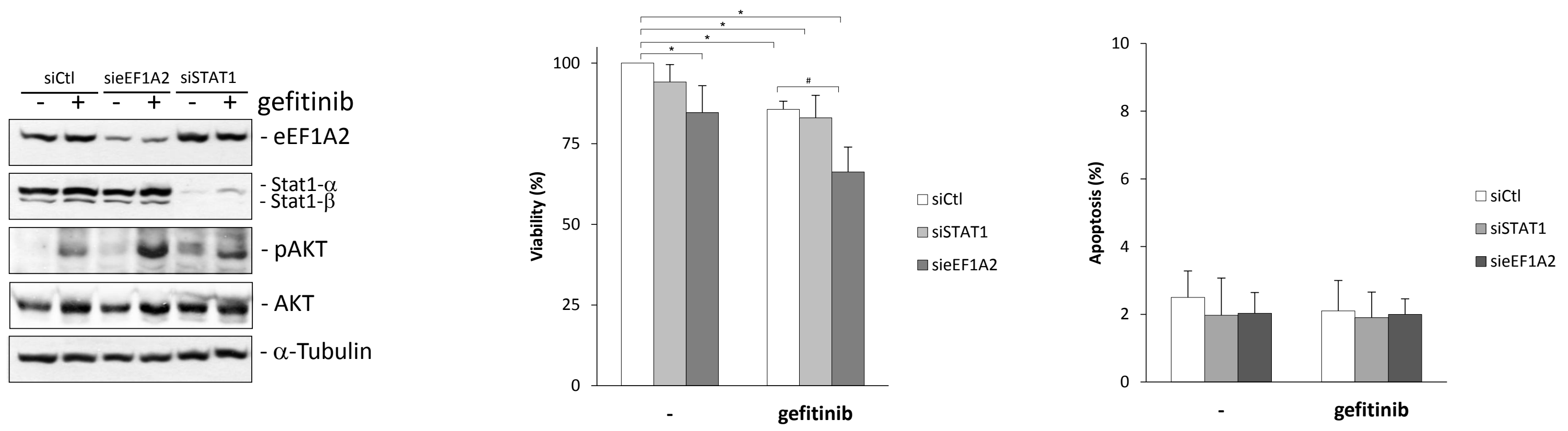

Figure 5. Effects of eEF1A2 and STAT1 silencing on AKT activation, cell viability and apoptosis. H358 cells were transfected with control siRNA (siCtl), eEF1A2 siRNA (sieEF1A2), or STAT1 siRNAs (siSTAT1) and treated with $0.5 \mu \mathrm{mol} / \mathrm{L}$ gefitinib. A: Representative immunoblots of eEF1A2, STAT1 and phosphorylated AKT (pAKT) in cells treated as indicated. a-tubulin was used as a protein level control. B: Cell viability in cells treated as indicated $(\mathbf{n}=3) .{ }^{*} p<0.05$ for comparison between treated and control; ${ }^{*} p<0.05$ for comparison between treated and gefitinib. $\mathrm{C}$ : Apoptosis was measured by flow cytometry analysis of active caspase-3 in cells treated as indicated $(n=3)$. 